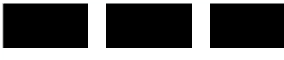

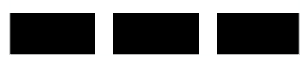

The WiLliam DAVIDSON INSTITUTE AT THE UNIVERSITY OF MICHIGAN BUSINESS SCHOOL

\section{Credit Market Disequilibrium in Poland: Can We Find What We Expect? Non-Stationarity and the "Min" Condition.}

\author{
By: Christophe Hurlin and Rafal Kierzenkowski
}

William Davidson Institute Working Paper Number 581

June 2003 


\title{
Credit Market Disequilibrium in Poland: Can We Find What We Expect? Non-Stationarity and the "Min" Condition*
}

\author{
Christophe Hurlin ${ }^{\dagger}$ and Rafał Kierzenkowski ${ }^{\ddagger}$
}

June 2003

\begin{abstract}
This paper presents an empirical investigation of the disequilibrium hypothesis on the Polish loan market in the 1990s. Using data over this period of deep transition, we estimate a disequilibrium model with a standard maximum likelihood method. However, the estimates are highly counter-intuitive as regards the timing of the identified regimes. We show that the gap between the econometric evidence and the expected results may stem from the issue of stochastic non-stationarity in a disequilibrium setting based on the "min" condition. We find that the omission of one non-stationary variable of the cointegrating space or the absence of a "structural" cointegrating relationship in one or both regimes lead to a spurious configuration. In such a case, using, wrongly, the standard likelihood function, derived under the hypothesis of stationarity, may lead to non-convergent estimates of structural parameters and, as a consequence, to a fallacious regimes identification. Therefore, as the first approach to this issue, we estimate a disequilibrium model with stationary data. The empirical results are then robust and economically founded and correspond to the set and the timing of anticipated regimes.
\end{abstract}

- Keywords : disequilibrium, monetary standard and regimes, non-stationarity and cointegration, transition, Poland.

- J.E.L Classification : D50, E42, C32, P00

\footnotetext{
${ }^{*}$ The authors are grateful to Jean-François Jacques for helpful comments and discussions. Many thanks go to people from the National Bank of Poland who provided an inestimable help in obtaining the time series used in this paper. The standard disclaimer applies. Comments are welcome.

${ }^{\dagger}$ LEO, Orléans University, Faculté de Droit, d'Economie et de Gestion, Rue de Blois - B.P. 6739, 45067 Orléans cedex 2. E-mail: christophe.hurlin@univ-orleans.fr

${ }^{\ddagger}$ CREFED-CERPEM, Paris Dauphine University, Place du Maréchal de Lattre de Tassigny, 75775 Paris cedex 16 (author responsible for correspondence). E-mail: rafal.kierzenkowski@dauphine.fr
} 


\section{Introduction}

The Polish credit market unquestionably experienced sharply contrasting evolutions in the 1990s. The difficulty of the monetary authority's control over credit activity was a permanent preoccupation during the Polish transition process, but the corresponding reasons changed dramatically over time. Between 1995 and 1998, the combination of fixed exchange rate policies and strong capital inflows led to a spectacular accumulation of foreign reserves by the central bank. The amount of gross official reserves expanded from USD 6 billion in 1994 to more than USD 28 billion in 1998. These liquidity inflows triggered off a boom in the credit market with the total amount of loans increasing from USD 17 billion to 38 billion over the same period. At the same time, the increasing performances and the constant improvement of banks' health along with harsh competition for customers could only have a favourable impact on the supply of credit. The rise in loan supply was so sensitive that it was largely disproportionate as compared with the change in loan demand over the period at issue. By and large, between 1995 and 1998, the banks' main problem was to find a sensible creditworthy borrower rather than the necessary funds for its financing. However, this situation changed suddenly in 1999. First, there was an increase in the instability of real activity. Whereas the average annual growth rate of GDP was nearly 6 per cent in the 1994-1998 period, it decreased to 4.1 per cent in 1999 and 4.0 per cent in 2000. It fell to only 1 per cent in 2001, reaching an all-time low of 0.2 per cent in the fourth quarter. Second, those economic events were concomitant with tremendous deterioration of the supply side of the credit market. Indeed, the ratio of non-performing loans to total loans upsurged from 10.9 per cent in 1998 to 13.7 per cent in 1999, and was exceeding 18 per cent at the end of 2001. Moreover, banks' profitability, as measured in terms of the gross profit to income ratio, tumbled from an average of 14.5 per cent between 1995 and 1998 to 4.5 per cent from 1999 to 2001. On the whole, since the end of 1999 banks have tried to preserve their activity by contracting their credit supply and investing in riskless assets. For these different reasons, it is highly probable that the Polish credit market was characterized by a disequilibrium state in the 1990s. The symptoms are so obvious that this is a textbook case for applying disequilibrium theories developed in the 1970s.

The first research objective of this paper is to confirm econometrically the switch observed in the Polish loan market and to test the disequilibrium hypothesis. In this respect, we apply standard methods issued from a behavior rule, the "min" condition, based on the voluntary exchange principle. The underlying idea is that the observed amount of loans is equal to the minimum of quantities demanded and supplied, which are assumed to be unobservable. A very important strand of the literature has been devoted to the estimation of this sort of models since the 1970s. Here, we adopt the standard maximum likelihood estimation method developed by Maddala and Nelson (1974). Yet, we show that the implementation of this technique does not allow to identify the type of disequilibrium a priori expected on the Polish loan market. The results are highly counter-intuitive, in particular as far as the identification of the regimes in the 1994:02-2002:02 period is concerned. Indeed, for all different specifications we obtain the opposite regimes to the ones we anticipated. The model generates a high estimated probability of a supply regime over the major part of the period under consid- 
eration and a demand regime at its end. These findings are robust to the specification choice but are completely at odds with the analysis one can make about the Polish loan market over the sample period. Therefore, it is important to understand the reasons for the existing gap between the econometric evidence and the expected results.

The bottom line of our paper is to give an insight into this empirical puzzle. More precisely, we call the attention on the phenomenon of stochastic non-stationarity in a disequilibrium setting. As a matter of fact, it appears that almost all of our series are non-stationary. Additionally, the assumption of cointegration is strongly rejected for most of the equilibrium linear specifications under study. In consequence, the question is to know how to use the concept of cointegration within a non-linear configuration such as the "min" condition given that, by definition, the loan demand and supply variables are unobservable.

As a matter of fact, we think that it is highly probable that there is no cointegrating relationship between the unobservable variables and the set of explanatory variables specified in each regime. Even considering that such a cointegrating relationship might exist, a simple specification error, like the omission of at least one non-stationary explicative variable in one of the two regimes would lead inexorably to the apparition of non-stationary residuals in one or both regimes. Yet, in that case (stemming from the absence of a "structural" cointegrating relationship or from the omission of one nonstationary variable of the cointegrating space), it is no longer possible to estimate the disequilibrium model using the maximum likelihood methodology proposed by Maddala and Nelson (1974). When residuals in at least one regime are non-stationary, the log-likelihood function is then asymptotically degenerated and its use in a estimation procedure would lead to a spurious estimation. As a result, the identified demand and supply regimes, based on non convergent estimates of structural parameters, may be aberrant. Ultimately, what is at stake is that one cannot test ex-post or ex-ante for the existence of a cointegrating relationship in each regime, i.e. for the stationarity of the residuals because the "true" demand and supply functions are by nature unobservable.

If this kind of configuration were to occur, just like for the linear models, the solution would consist in identifying the demand and supply regimes using stationary variables in levels or variables stationarized by differencing. That is why we present in this paper a first approach to dealing with this problem that consists in estimating a disequilibrium model with stationary data. If there is disequilibrium between loan demand and supply it clearly appears that there are necessarily at least two regimes when using the stationary transform (annual growth rate or long difference) of the observed quantity of credit. The only difference being that the switching regime rule is no longer the "min" condition. Nevertheless, as the first approximation we propose to use a standard $M L$ procedure framework by estimating a model with stationary data and containing the "min" condition. First, it appears that the obtained results are robust and economically founded. In the most sophisticated specifications all coefficients have the expected sign and virtually all variables are statistically significant. Second, and more importantly, the set and the timing of regimes we identify are in line with the stylized facts pertaining to the history of the Polish loan market. Even though this solution to the issue of non-stationarity in the absence of cointegrating relationship 
(spurious regression configuration) is not completely satisfactory, it is a first step in the right direction. It clearly shows that in the Polish case, if relevant, the identification of regimes must be done with the stationary components of both the amount of credit and the observable explanatory variables, and not directly with the variables in levels.

Overall, considering the Polish loan market disequilibrium in the 1990s, the main finding of the paper at hand is that the identification of a disequilibrium in the loan market with a model containing the "min" condition cannot be done with non-stationary data. The upshot is that the identification of different regimes and hence the assessment of the disequilibrium should be made with stationary components of the variables.

The paper is organized as follows. In section 2, we briefly recall the traditional maximum likelihood method for estimating models of markets in disequilibrium. In section 3, the results obtained on the Polish credit market are presented and compared to the main stylized facts. Section 4 exposes the main issues of the non-stationarity in a disequilibrium representation. In section 5 , we propose estimates for a disequilibrium model with stationary data and section 6 concludes the paper.

\section{Disequilibrium econometrics: the "min" condition}

Since Fair and Jaffee (1972) an important literature has been devoted to the econometric problems associated with estimating demand and supply schedules in disequilibrium markets. The main approach consists in using some maximum likelihood $(M L)$ methods. In a seminal paper, Maddala and Nelson (1974) derived the general likelihood function for different disequilibrium models and proposed the appropriate $M L$ estimating procedures. The simplest model considered by the authors is as follows:

$$
\begin{aligned}
d_{t} & =x_{1, t}^{\prime} \beta_{1}+\varepsilon_{1, t} \\
s_{t} & =x_{2, t}^{\prime} \beta_{2}+\varepsilon_{2, t} \\
q_{t} & =\min \left(d_{t}, s_{t}\right)
\end{aligned}
$$

where $d_{t}$ denotes the unobservable quantity demanded during period $t, s_{t}$ the unobservable quantity supplied during period $t, x_{1, t}^{\prime}=\left(x_{1, t}^{(1)} x_{2, t}^{(1)} \ldots x_{K_{1}, t}^{(1)}\right)^{\prime}$ is a vector of $K_{1}$ explanatory variables that influence $d_{t}, x_{2, t}^{\prime}=\left(x_{1, t}^{(2)} x_{2, t}^{(2)} \ldots x_{K_{2}, t}^{(2)}\right)^{\prime}$ is a vector of $K_{2}$ explanatory variables that influence $s_{t}, \beta_{1}$ and $\beta_{2}$ are respectively $\left(K_{1}, 1\right)$ and $\left(K_{2}, 1\right)$ vectors of parameters. We assume that $d_{t}$ and $s_{t}$ are unobservable at date $t$, whereas $x_{1, t}$ and $x_{2, t}$ are observable. The variable $q_{t}$ denotes the actual quantity observed at time $t$. The equation (3) is the crucial disequilibrium hypothesis, which allows for the possibility that the price of the exchanged good is not perfectly flexible and rationing occurs. More generally, (3) indicates that any disequilibrium which takes place, i.e. any divergence between the quantity supplied and demanded, results from lack of complete price adjustment. Therefore, on the basis of voluntary exchange the "short side" of the market prevails. Because of the equation (3), the model itself determines the probabilities with which each observation belongs to either supplied or demanded quantities. In what follows, we briefly develop the theoretical underpinnings of this result. 
In a first version of the model, Maddala and Nelson (1974) assume that both residuals $\varepsilon_{1, t}$ and $\varepsilon_{2, t}$ are stationary processes, independently and normally distributed with variance $\sigma_{1}^{2}$ and $\sigma_{2}^{2}$ respectively. Under these regularity assumptions, the transformed variable $\varepsilon_{1, t}-\varepsilon_{2, t}$ is normally distributed with a variance equal to $\sigma^{2}=\sigma_{1}^{2}+\sigma_{2}^{2}$. Hence, the reduced variable $\left(\varepsilon_{1, t}-\varepsilon_{2, t}\right) / \sigma$ follows a $N(0,1)$. Then, the probability that the observation $q_{t}$ belongs to the demand regime, denoted $\pi_{t}^{(d)}$, can be computed as the corresponding $N(0,1)$ fractile:

$$
\pi_{t}^{(d)}=P\left(D_{t}<S_{t}\right)=\Phi\left(h_{t}\right)=\frac{1}{\sqrt{2 \pi}} \int_{-\infty}^{h_{t}} e^{-\frac{x^{2}}{2}} d x
$$

where $h_{t}=\left(x_{2, t}^{\prime} \beta_{2}-x_{1, t}^{\prime} \beta_{1}\right) / \sigma$, and $\Phi(x)$ denotes the cumulative distribution function of the $N(0,1)$. Symmetrically, the probability to get the supply regime, denoted $\pi_{t}^{(s)}$, is defined by $P\left(S_{t}<D_{t}\right)=1-\Phi\left(h_{t}\right)$.

Let $\theta$ denote the vector of structural parameters $\theta=\left(\beta_{1} \beta_{2} \sigma_{1} \sigma_{2}\right)^{\prime}$. In order to compute the marginal density, $f_{Q_{t}}\left(q_{t}\right)$, of the observable variable $q_{t}$, we consider the joint density of $d_{t}$ and $s_{t}$, denoted $g_{D_{t}, S_{t}}\left(d_{t}, s_{t}\right)$. Given the definition of the disequilibrium, we know that:

$$
f_{Q_{t}}\left(q_{t}\right)=f_{Q_{t} \mid D_{t}<S_{t}}\left(q_{t}\right)+f_{Q_{t} \mid S_{t}<D_{t}}\left(q_{t}\right)
$$

Then, we get the corresponding marginal density of $q_{t}$ on the two subsets (cf. Appendix (A.1)):

$$
\begin{aligned}
& f_{Q_{t} \mid D_{t}<S_{t}}\left(q_{t}\right)=\int_{q_{t}=d_{t}}^{\infty} g_{D_{t}, S_{t}}\left(d_{t}, z\right) d z \\
& f_{Q_{t} \mid S_{t}<D_{t}}\left(q_{t}\right)=\int_{q_{t}=s_{t}}^{\infty} g_{D_{t}, S_{t}}\left(z, s_{t}\right) d z
\end{aligned}
$$

Finally, we obtain the unconditional density function of $Q_{t}$ :

$$
f_{Q_{t}}\left(q_{t}\right)=f_{Q_{t}}\left(q_{t}, \theta\right)=\int_{q_{t}}^{\infty} g_{D_{t}, S_{t}}\left(q_{t}, z\right) d z+\int_{q_{t}}^{\infty} g_{D_{t}, S_{t}}\left(z, q_{t}\right) d z
$$

Next, conditionally to a structural parameters set $\theta$ and a sample of observable variables $q_{t}, x_{1, t}$ and $x_{2, t}$ observed on $T$ periods, the log-likelihood function of the model is then defined by:

$$
L(\theta)=\sum_{t=1}^{T} \log \left[f_{Q_{t}}\left(q_{t}, \theta\right)\right]
$$

If we assume that both residuals $\varepsilon_{1}$ and $\varepsilon_{2}$ are independent, the unconditional density function of $Q_{t}$ can be expressed as follows:

$$
\begin{aligned}
f_{Q_{t}}\left(q_{t}\right)= & \frac{1}{\sigma_{1}} \phi\left(\frac{x_{1, t}^{\prime} \beta_{1}-q_{t}}{\sigma_{1}}\right) \Phi\left(\frac{x_{2, t}^{\prime} \beta_{2}-q_{t}}{\sigma_{2}}\right) \\
& +\frac{1}{\sigma_{2}} \phi\left(\frac{x_{2, t}^{\prime} \beta_{2}-q_{t}}{\sigma_{2}}\right) \Phi\left(\frac{x_{1, t}^{\prime} \beta_{1}-q_{t}}{\sigma_{1}}\right)
\end{aligned}
$$


where $\phi($.$) denotes the normal N(0,1)$ density function. The proof is provided in Appendix (A.1). In this case, the first and second order derivatives of $L(\theta)$ can be computed analytically (Maddala and Nelson, 1974) or numerically. We can use an iterative procedure like the Newton-Raphson procedure to obtain the $M L$ estimates of the structural parameters $\theta$. Given the estimated values of the parameters, we can compute the estimated probability that the observation $q_{t}$ belongs either to the demand or the supply regime, $\widehat{\pi}_{t}^{(d)}$ and $\widehat{\pi}_{t}^{(s)}$.

\section{Credit market in Poland and disequilibrium}

We now propose to estimate a disequilibrium model on the credit market in Poland during the 1990s. For different reasons already exposed in the introduction, such a model may be a priori a good representation of the evolution of the credit market conditions.

\subsection{Data description}

Our data set covers the period from February 1994 to February 2002, including 97 monthly observations. All data are obtained from the National Bank of Poland (hereafter NBP), except the industrial production $\left(P R O D_{t}\right)$ and import prices $\left(I M P_{t}\right)$, which come from the Monthly Bulletin publication of the Polish Central Statistical Office (GUS).

Most of the series used in this study are defined for a set of banks. The sample includes 20 banks in February 1994 and 11 in February 2002 (the difference due to the consolidation process). It represents on average for the period under consideration 75.3 per cent of the banking system in terms of total corporates' banking debt and 84.7 per cent in terms of total deposits. The variables calculated for our sample of banks pertain to residents and non residents sectors and are defined as follows. For the loan series, $Q_{t}$, we use total zloty denominated loans up to one year extended to the Polish corporate sector $^{1}$. This series represents on average for the period under consideration 36.5 per cent of total credit extended to firms for our sample of banks, and 27.5 per cent taking the whole Polish banking sector. The loan interest rate, $I L_{t}$, is an arithmetical mean of 3-month, 6-month and 1-year weighted averages for minimum loan rates applied to Polish firms. As for total deposits, $D E P_{t}$, we use the sum of demand and time zloty and foreign currency deposits and of interests on those deposits of both households and firms, whereas time deposits, $S A V_{t}$, are defined only for firms and also include interests on deposits. Lastly, the $O L_{t}$ variable, concerns only the corporate sector and is defined as the following ratio: zloty denominated loans beyond one year plus total foreign currency loans divided by total extended loans.

The remaining series are defined at the aggregate level. The intervention rate of the central bank, $I C_{t}$, is a weighted average of 1 to 14-day reverse operation rates and that of the central bank securities issued for different maturities between February 1994 and January 1998. Since then, it is equal to the actual rate on 28-day NBP bills

\footnotetext{
${ }^{1}$ The "corporate sector" includes state-owned enterprises, private enterprises with up to 9 or more employees, cooperatives, and farmers.
} 
(also taking into account the average rate of outright operations). The variable called $L N F A_{t}$ is the ratio of net foreign assets of the central bank to the overall value of banking funds absorbed by sterilization operations led by the NBP, which include the net value of reverse repos, outright and NBP bills issue operations and the value of required reserves. Finally, $A T B_{t}$ measures the share of Treasury bills to total banking assets.

In all models the variables are in nominal terms, expressed in logarithm, except for the interest rates which are measured in percentage points.

\subsection{Estimation results}

One of the main issue in disequilibrium models is the specification choice of both regime equations. Since demand and supply are not continuously observable, a specification error (the omission of an explicative variable in $x_{1, t}$ or $x_{2, t}$ for instance) can lead to the non relevance of one of the assumptions used in the construction of the likelihood function $\left(\varepsilon_{j, t}\right.$ i.i.d. for instance). The estimates $\widehat{\theta}$ are then derived from an inadequate $M L$ procedure and the fit $\widehat{s}_{t}$ and $\widehat{d}_{t}$ may be based on biased estimates of structural parameters. Consequently, it is difficult to test ex-post the presence of a specification error since the true processes, $s_{t}$ and $d_{t}$, are unobservable. This is why we consider several specifications of the disequilibrium models on the Polish loan market. The results are reproduced in Table (1).

- Insert Table 1

In the first specification (model 1), the loan demand and supply equations are each assumed to be described by only one variable. More precisely, $D E P_{t}$, which denotes total zloty and foreign currency deposits of households and firms, is expected to have a positive coefficient in the loan supply equation. $S A V_{t}$ is a proxy for firms' cash flow and is expected to have a negative impact on loan demand. First, as we can see from Table (1), both variables are significant, but the coefficient of the firms' cash flow has the wrong sign. Second, and more strikingly, the adjusted R-squared statistics is also very high (almost equal to 1 ), as is the t-statistics of the $D E P_{t}$ variable. Finally, we note that the frequency of the supply regime amounts to 82 per cent.

The drawback of estimating model 1 is that there is only one variable specific to each function. Therefore we include several additional variables in model 2 in order to better discriminate between loan demand and supply. The loan interest rate, $I L_{t}$, is expected to have a negative sign in the demand function and a positive sign in the supply one. Due to the substitution effect, the intervention rate of the NBP, $I C_{t}$, should have the opposite sign to $I L_{t}$ in both equations. In the disequilibrium loan market literature ${ }^{2}$, a lagged index of industrial production is often used to approximate the firms' and the banks' expectations about future economic activity and to have a positive coefficient. Following the Bernanke and Blinder's (1988) model and the bank lending channel literature, a positive dependence of loan demand on output is assumed due to working capital or liquidity considerations. Yet, the latter assumption is rather ambiguous if the corporate sector loan demand is considered. As a matter of fact, a

\footnotetext{
${ }^{2}$ See, for instance, Sealey (1979), Kim (1999), Pazarbaşioğlu (1997).
} 
drop in industrial production will probably strengthen the liquidity constraint of firms, thus increasing their short-term credit demand. Gertler and Gilchrist (1993), Dale and Haldane (1995) among others, find a short-term increase in bank lending to the corporate sector in the wake of tight money. Given these arguments, the theoretical sign of the parameter of industrial production, $P R O D_{t}$, is indeterminate. The results of estimates of model 2 indicate that the parameters of all variables are significant and, except $S A V_{t}$, have the expected signs. Moreover, the frequency of the loan demand regime increased to 28 per cent, but the quality of the model, as measured by the value of the log-likelihood, improved only slightly.

In order to verify the robustness of the latter findings, we estimated a third model with two additional variables as compared with model 2 . The purpose of the first one, $O L_{t}$, is to capture the impact of other loans extended to the corporate sector. Introduced in the loan demand equation, the corresponding coefficient is expected to have a positive sign in the case of complementary effects or a negative one if other banking means can be substituted for zloty denominated loans up to one year. The second variable, $A T B_{t}$, is a rough measure of the imperfect substitutability between bonds and loans mainly due to changes in the riskiness of financial intermediation. It is expected to bear a negative coefficient in the loan supply function. Although the extra variables are significant and the coefficient of $A T B_{t}$ has the predicted sign, the results reported for model 3 in Table (1) clearly reveal that, except the intervention rate in loan demand equation, the interest rates in both loan demand and supply equations are no longer significant. What is worse is that three out of four parameters do not have the expected sign. Nevertheless, the quality of the model increased with regard to the value of the $L$ statistics, but the split between the two regimes has remained unchanged.

Until now none of the variables does explicitly take into account the openness of the Polish economy and its impact on the credit market. Consequently, we deal with this issue by introducing two additional variables. On the supply side of the market, $L N F A_{t}$ aims at measuring the net liquidity impact on banks of the foreign reserves accumulation by the central bank due to the exchange rate intervention. One could claim that $L N F A_{t}$ is no longer an appropriate indicator since the implementation of the floating exchange rate system, i.e. since at least June $1999^{3}$. However, according to OECD (2001), the NBP continued to make off market foreign exchange transactions as an agent of the government in 2000 and early 2001. This had the same impact on banking liquidity than market interventions. On the demand side of the market, we include the index of import prices, $I M P_{t}$, which is expected to have a positive coefficient. The idea behind introducing this variable is that a change in import prices of intermediate and industrial goods will directly affect the production costs of firms and hence their loan demand ${ }^{4}$. As for the model 3 estimates, both supplementary variables turn out to be significant and their coefficients have the expected signs. Despite huge sterilization operations, the heavy build-up of the NBP's net foreign assets appears to have a positive impact on loan supply, whereas changes in import prices also come into

\footnotetext{
${ }^{3}$ Date at which the NBP definitively stopped its foreign exchange market interventions by abolishing fixing transactions.

${ }^{4}$ It should be noted that in the second half of the nineties, the imports to GDP ratio was about 10 per cent in Poland.
} 
Figure 1: Estimated Probabilities of Each Regime, III/94 - II/02

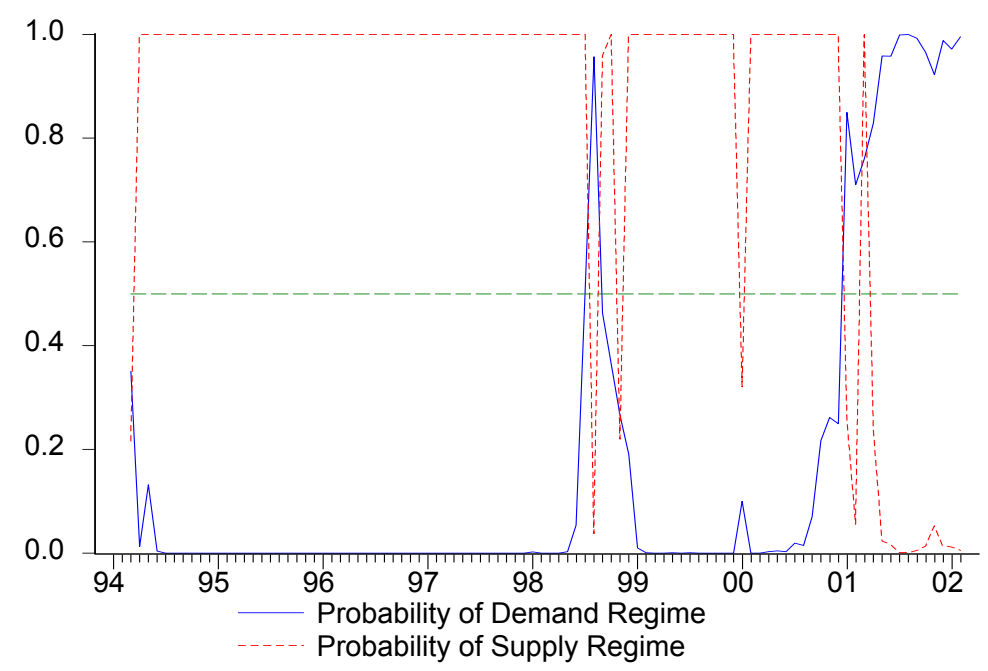

play in the credit behavior of firms. Nonetheless, apart from the loan interest rate in the demand equation other interest rates still lack statistical significance and the loan interest rate parameter in the supply equation is wrongly signed. In model 5 , we checked whether these findings are not driven by some collinearity problems between the interest rates. To this end, we used the spread, $I L_{t}-I C_{t}$, and the intervention rate, $I C_{t}$, instead of $I L_{t}$ and $I C_{t}$ in each equation. The results reported in Table (1) are identical to those of model 4 . When introducing a one lag structure on the interest rates as in model 6 , both interest rates in the loan demand equation have the expected sign and statistically significant coefficients. But, concerning the loan supply interest rate coefficients, the problem still persists. Yet, the quality of the model improves as it leads to a higher value of the $L$ statistics.

To sum up, when applying the Maddala and Nelson (1974) approach to the Polish loan market, the coefficients of some variables, especially those of interest rates, are not significant and/or do not bear the expected sign. Actually, this is particularly true for the loan interest rate in the supply equation. More generally, finding that, whatever the side of the market, interest rates do not seem to play a significant role or even act in the opposite direction to what one could expect is puzzling. However, these observations are not the most worrisome. Our estimates reveal the existence of a succession of two regimes. Figure (1) shows the estimated probabilities of each regime for the best model in terms of the log-likelihood statistics, i.e. for model 6. It appears that the loan market was characterized by an almost permanent and strong supply regime until the end of 2000. A demand regime unambiguously have emerged since the beginning of 2001. It should be noted that these results seem robust since models 1, 2, 3 , and 4 yielded very similar configurations of both regimes. 
These results on the timing of supply and demand regimes are undoubtedly not representative of the recent history of the Polish loan market.

First, fixed exchange rate policies followed until at least June 1999 can be expected to have had a positive, long-standing and pronounced impact on the loan supply. On the one hand, sterilization operations of capital inflows created since the end of 1993 a structural overliquidity of the banking system, defined as a net indebtedness of the central bank towards commercial banks. They potentially rendered demand regimes much more likely. At the same time, since these capital inflows were in fact imperfectly sterilized $^{5}$, they also had a direct favorable impact on loan supply. In the light of these facts, the finding of a supply regime in the 1990s does not seem plausible.

Second, banks' health considerably improved since 1994. Actually, the share of non-performing loans in total loans for enterprises and households decreased steadily from 31 per cent in 1993 to 28.7 per cent in 1994 reaching a low point of 9.8 per cent in September 1997. However, the ratio experienced an upsurge from 10.9 per cent in December 1998 to 13.7 per cent in December 1999, and attained a 18.3 per cent level in December 2001 (for the corporate sector only, the corresponding figures were 11.9, 15.1, and 20.4 per cent, respectively). Obviously, these stylized facts lead us to expect the opposite regimes to the one we obtained by the estimates.

Third, a credit boom occurred in the loan market from mid-1996 to mid-1997. As of December 1996, in order to curb the credit expansion, the central bank started to tighten up progressively its monetary policy by rising both the interest rates and the reserve requirement ratios. However, considering that these measures did not yield the expected results on banks' behavior, thereby recognizing the failure of the traditional monetary instruments, the central bank resorted to an exceptional measure. In September 1997 it started to accept deposits directly from the public. Again, these observations strongly suggest that the credit boom was rather led by supply factors and not demand-driven.

Insert Table 2

Fourth, although 1993 is often considered in the literature as a typical "credit crunch" year due to the "bad-loans" problem underwent by the Polish banking sector in the wake of the 1990-1991 transformational recession, it does not necessarily imply that this state of the market prevailed in the subsequent years. This lends support to the fact that following the governmental recapitalization program $^{6}$, we should expect the opposite. What needs to be stressed here is that in 1994 the level of credit, measured by the ratio of credit to the corporate sector to GDP (see Table (2)) was extremely low hardly reaching 17.1 per cent of GDP. Therefore, a strong increase in its volume was likely to occur. Moreover, in the same year, there was an almost 40 per cent decline of the ratio as compared with 1989, and a 25 per cent as compared with 1991. As a result, if since 1994 banks might have wanted to build up their market shares on a healthy basis again, then we should observe a demand regime in the 1990s rather than a supply one.

\footnotetext{
${ }^{5}$ Bofinger and Wollmershäuser (2002) find in the Polish case an absolute sterilization coefficient equal to 0.89 over the period from 1991:12 to 1998:09.

${ }^{6}$ Taking the average current exchange rate for each year, the govermental recapitalization amouted to USD 1.14 billion in 1993 and USD 1.75 USD billion in 1994.
} 


\section{Disequilibrium representation and non-stationarity}

Hence, the issue is to understand how such unexpected results can be obtained from the standard method of estimating disequilibrium models. There are three main competing explanations, which may lay at the root of our striking findings. The first concerns the reliability of the estimation procedure, the second deals with the "min" condition used to represent the credit market disequilibrium and the third concerns the empirical reliability of the disequilibrium assumption for the Polish credit market. However, our interpretation consists to add a fourth explanation based on the non-stationarity of the data used in this exercise.

\subsection{How to interpret the estimation results?}

The first source of explanation may be linked to the $M L$ estimation technique used to identify the demand and supply regimes. Two issues are worth mentioning as regards the estimation technique. The first is linked to the convergence of the iterative procedure. Indeed, the optimization method of the log-likelihood function $L(\theta)$ (equation (9)) should be handled very carefully since the global concavity of $L(\theta)$ is not assured. For instance, when one chooses one or both of the variance residuals $\sigma_{i}$, close to 0 , the function $L(\theta)$ converges toward infinity. Let us consider positive finite values for $\beta_{1}, \beta_{2}$ and $\sigma_{2}$. In this case, the second member of (10) is finite. But, the first term is degenerated if $\sigma_{1}$ converges to zero:

$$
\frac{1}{\sigma_{1}} \phi\left(\frac{x_{1, t}^{\prime} \beta_{1}-q_{t}}{\sigma_{1}}\right) \Phi\left(\frac{x_{2, t}^{\prime} \beta_{2}-q_{t}}{\sigma_{2}}\right)
$$

Indeed, if $\sigma_{1}$ converges to zero, $1 / \sigma_{1} \phi($.$) converges to \infty$, since given the properties of the normal distribution, $\lim _{x \rightarrow \infty} x \phi(x)=\infty$. The term $\Phi($.$) converges to 1$ since $\lim _{x \rightarrow \infty} \Phi(x)=1$. By analogy, the same analysis applies to the second member of $(10)$, which is degenerated if $\sigma_{2}$ converges to zero for given positive finite values of $\beta_{1}, \beta_{2}$ and $\sigma_{1}$. Then, the global maximum of the likelihood function is infinity, if one of the residual variances (or both) converges to zero. Therefore, the application of the standard $M L$ procedure should be adapted in this case as only local maximum must be searched for. That is why in our application we use three different algorithms of optimization in order to evaluate the robustness of our estimates: $(i)$ Newton Raphson with numerical or analytical gradient and Hessian matrix (ii) Nelder-Mead simplex method (iii) Newton Raphson with non-negativity constraints on $\sigma_{i}$.

The second concern refers to the starting values used for the optimization algorithms. There are various methods to obtain the initial conditions on structural parameters $\theta$ used in the $M L$ optimization. Here, we use a two step $O L S$ procedure detailed in Appendix (A.2). This procedure applied to artificial data leads to the convergence of all the optimization algorithms used and gives estimates, which are very close to the true set of parameters. As a result, it does not seem the right direction for finding the explanation of our striking empirical results.

The second potential explanation deals with the choice of the "min" condition, which might be an inadequate way to describe the disequilibrium in the loan market. 
Figure 2: Correlations of Changes in the Spread with Changes in the Intervention Rate Over Time, III/96 - II/02

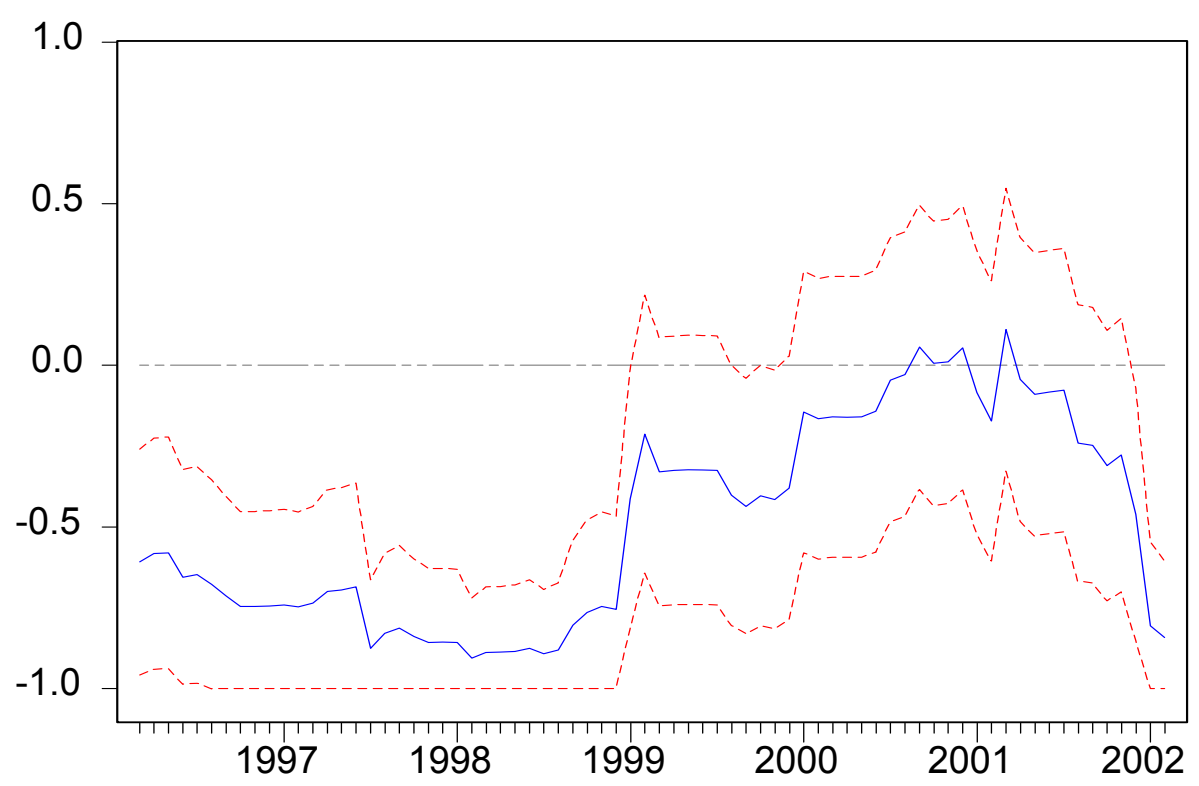

Yet, it seems important to note that this class of models has robust microfoundations from the "short side" rule, with a theoretical justification based on the voluntary exchange principle. Rather, the problem can stem from the known issue of aggregation. As aggregate data are averages of corporate data, some firms may be credit constrained whereas the average firm may not (Perez, 1998).

The third preoccupation is related to the empirical validity of the disequilibrium assumption in the Polish case. For the reasons already exposed, it seems clear that a modification of the credit market conditions occurred in the end of the 1990s. However, this change does not necessarily imply that the disequilibrium representation matches the Polish stylized facts. Another way to check the disequilibrium hypothesis is to evaluate the transmission of the monetary policy. Actually, if the price of loans is not perfectly flexible and does not clear the loan market, i.e. if the disequilibrium hypothesis is relevant, then, at first sight, we should not observe a smooth transmission of monetary policy controlled interest rates to loan rates. Opiela (1999) provides evidence for Poland that the responsiveness of loan rates to policy-influenced rates was less than 1 over the period from 1994:01 to 1998:03. We find the same result with our data set when we compute a set of rolling correlations of monthly changes in the intervention rate, $I C_{t}$, with monthly changes in the spread between the loan rate, $I L_{t}$, and the intervention rate. For each month in our sample a correlation coefficient is estimated using a 24month moving window of data.

As can be seen from Figure (2), the estimated correlation coefficient remains signif- 
icantly negative and stable until November 1998, signalling a substantial lending rate stickiness to changes in the policy controlled interest rate. Since then, and except for the end of the period, the correlation coefficient is almost never significantly different from zero indicating a good adjustment of the loan rate to changes in the policy rate. However, even if both interest rates move in tandem it does not necessarily preclude the existence of a disequilibrium in the credit market. Indeed, the adjustment of the loan rate may be still insufficient in order to clear the loan market.

Figure 3: Kernel Density of the Annual Growth Rate of the Quantity of Loans to the Corporate Sector

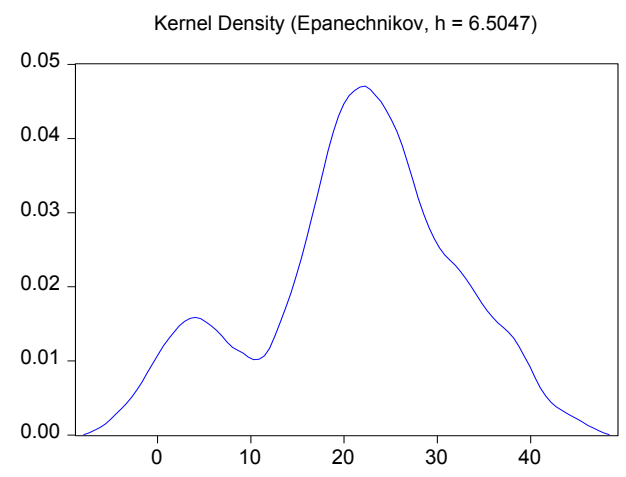

Finally, the last argument in favor of the disequilibrium hypothesis on the Polish credit market is the following. Figure (3) represents the Kernel density estimates of the annual growth rate of loans to the corporate sector. As we can see, the empirical density has the general form of a mixture of normal distributions. Such observation is particularly compatible with a disequilibrium model in which the "short side" of the market prevails.

\subsection{The non-stationarity hypothesis}

Here, we propose another potential explanation for our results. For several reasons, the focus of the discussion is shifted to the issue of non-stationarity of the data used in the estimates. We call attention to this problem since, except for the interest rates, virtually all the observed variables used in the disequilibrium models are $I(1)$ processes. The results of unit root tests are reported in Appendix (A.3). If the loan market was continually in equilibrium, the following standard approach would be adopted. The model would simply be estimated using a linear specification, i.e. by regressing the observed amount of loans on all the explanatory variables of both loan demand and supply functions. The estimates would be made in levels in the presence of a cointegrating relationship and in first differences otherwise. At least in models 1 and 2, the cointegration tests in linear models indicate the absence of cointegration relationship. So, if the disequilibrium hypothesis is rejected in these models, the linear representation of the observed quantity of loans must be based on the first differences of the non-stationary series. How does it look like in the disequilibrium representation? How 
can we transpose the concepts of cointegration if the equilibrium assumption is violated and the loan market can be described by a disequilibrium model with a "min" condition? What are the consequences of the use of the standard $M L$ procedure when the cointegration is rejected in one of the two regimes?

In order to precise the influence of non-stationarity in the "min" representation, let us consider the initial model (equations (1), (2) and (3)) and assume that all observed explicative variables $x_{j, t}^{(i)}$ are generated by an integrated stochastic process. For simplicity, let us assume a pure random walk process $\forall j=1, . ., K_{i}, \forall i=1,2$ :

$$
\Delta x_{j, t}^{(i)}=\mu_{j, t}^{(i)}
$$

where the innovations processes $\mu_{j, t}^{(i)}$ are i.i.d. We also assume that both demand $d_{t}$ and supply $s_{t}$ are integrated processes. As a result, two configurations appear: the first called the cointegrating representation and the second called the spurious regression representation.

In the first case, we have, in each regime, a linear relation between a non-stationary unobservable dependent variable and non-stationary explicative variables $x_{j, t}^{(i)}$. We further assume that, in each regime, there is a cointegrating relationship between these variables represented by:

$$
\begin{aligned}
& d_{t}=x_{1, t}^{\prime} \widetilde{\beta}_{1}+\eta_{1, t} \\
& s_{t}=x_{2, t}^{\prime} \widetilde{\beta}_{2}+\eta_{2, t}
\end{aligned}
$$

where processes $\eta_{1, t}$ and $\eta_{2, t}$ are $I(0)$. In this case, the log-likelihood of the observation $q_{t}$ is well-defined since the regularities assumptions are satisfied. The maximum likelihood methods can be applied to estimate the parameters of the models and to identify the corresponding regimes. If we also assume that there is a cointegrating relationship between the demand $d_{t}$, and the supply $s_{t}$, i.e. these unobservable variables share the same common stochastic trend, then the model can be rewritten as:

$$
\begin{aligned}
d_{t} & =x_{1, t}^{\prime} \widetilde{\beta}_{1}+\eta_{1, t} \\
s_{t} & =d_{t}+\zeta_{t}
\end{aligned}
$$

where the process $\zeta_{t}$ is stationary. In this case, we can also apply the Laroque and Salanié (1997) strategy based on a first differences final form.

In the second case, i.e. the spurious regression representation, we also have a linear relation between a non-stationary unobservable dependent variable and non-stationary explicative variables $x_{j, t}^{(i)}$. But we assume that, in each regime, there is no cointegrating relationship between these variables. In other words, we have:

$$
\begin{aligned}
& d_{t}=x_{1, t}^{\prime} \beta_{1}+\varepsilon_{1, t} \\
& s_{t}=x_{2, t}^{\prime} \beta_{2}+\varepsilon_{2, t}
\end{aligned}
$$

where $\varepsilon_{1, t}$ and $\varepsilon_{2, t}$ are $I(1)$ processes. It should be noted that such a framework does not necessarily imply the absence of a long run relationship between $d_{t}$ and $s_{t}$. The 
problem in this case is that the likelihood of the disequilibrium model is asymptotically degenerated since the residuals do not have a stationary distribution. The standard $M L$ procedure is then not appropriate asymptotically since the marginal distribution (10) of $q_{t}$ is not well defined. For a finite sample, when considering wrongly the Maddala and Nelson's likelihood function, the numerical optimization may not converge or may converge, but then leads to non-convergent estimates of the structural parameters. Thus, the identification of the supply and demand regimes becomes impossible or fallacious.

What is the most plausible representation? It is undoubtedly the second one. Indeed, in this context a simple specification error, as the omission of an integrated regressor, leads to the apparition of the spurious regression representation. For instance, let us assume that the cointegrating representations (12) and (13) are the true ones and that we make a specification error in the estimation of the model. If we note $\widetilde{x}_{1, t}$ the vector of explicative variables used in which we omit for instance the $K_{1}^{t h}$ element of the true vector $x_{1, t}$. The excluded element, denoted $x_{K_{1}, t}^{(1)}$, is by construction $I(1)$. Then we have:

$$
d_{t}=x_{1, t}^{\prime} \widetilde{\beta}_{1}+\eta_{1, t}=\widetilde{x}_{1, t}^{\prime} \beta_{1}+x_{K_{1}, t}^{(1)} \beta_{K_{1}}^{(1)}+\eta_{1, t}=\widetilde{x}_{1, t}^{\prime} \beta_{1}+\varepsilon_{1, t}
$$

where the residual $\varepsilon_{1, t}=x_{K_{1}, t}^{(1)} \beta_{K_{1}}^{(1)}+\eta_{1, t}$ is non-stationary and may be identified to the residual of equation (16). In this false specification, we do not have a cointegrating relationship between $d_{t}$ and the specified set of cointegrating variables. Yet, the central issue is that we cannot test for the existence of a cointegrating relationship between $d_{t}$ and the explanatory variables since the demand $d_{t}$ is unobservable. Even for periods when the demand regime occurs (i.e. $q_{t}=d_{t}$ ) it is not possible to test the cointegrating relationship since the likelihood is not defined for non-stationary residuals. Moreover, even ex-post it is impossible to test for a cointegrating relationship because the estimates of $d_{t}$ and $s_{t}$ are derived from the maximization of a degenerated function. All in all, a specification error in both unobservable regimes or even the simple omission of at least one integrated regressor can lead to the spurious regression representation.

\section{The disequilibrium model with stationary data}

The previous section revealed that the non-stationarity of our data could lead, in the absence of a cointegrating relationship between the unobservable variable and the corresponding set of explanatory variables (which is a highly probable outcome), to a fallacious identification of regimes. In order to detect whether such a configuration is responsible for our striking results on the Polish loan market, we propose here to identify the disequilibrium in a regime perspective, but not necessarily with a "min" condition. The idea behind this first approximation is as follows. If the true data generating process of $q_{t}$ is such as $q_{t}=\min \left(d_{t}, s_{t}\right)$, the dynamic of any linear transformation of the loan variable must satisfy at least two regimes. In particular, the first-differences series $\Delta q_{t}$ (or the long difference $\Delta_{z} q_{t}=q_{t}-q_{t-z}$ ) follows a four-regime dynamics, where there are two regimes of statu-quo with demand superior (or inferior) to supply at two points in time $(t$ and $t-1$, or $t$ and $t-z)$ and two regimes of switch from 
demand to supply or vice versa. Then, the idea is to identify the disequilibrium regime with stationary transformations of data as we would realize in a linear representation. In such configuration the main difficulty is to define the transition rule (which is not exactly the "min" condition) and to identify both switching regimes for which we can reasonably think that there are very few observations. For instance, in an eight-year sample, we can expect at most two or three changes of regimes from a demand regime to a supply one or vice versa. As a result, in order to identify the disequilibrium on the credit market with stationary series, a two-regime model is more plausible and technically more feasible than a four-regime one.

In this section, we analyze the disequilibrium in the loan market using stationary data. More precisely, we achieve stationarity by applying long differences (more precisely, annual growth rates) to each series, with the exception of the interest rates, which are stationary in levels. In such a setting, the disequilibrium model with the "min" condition from the previous section should simply be considered as a regimeswitching model among others with a contemporaneous threshold variable. We now consider the following model:

$$
\begin{aligned}
\Delta d_{t} & =\Delta x_{1, t}^{\prime} \beta_{1}+\mu_{1, t} \\
\Delta s_{t} & =\Delta x_{2, t}^{\prime} \beta_{2}+\mu_{2, t} \\
\Delta q_{t} & =\min \left(\Delta D_{t}, \Delta S_{t}\right)
\end{aligned}
$$

where $\Delta d_{t}$ denotes the annual growth rate of the unobservable demanded quantity of loans during period $t, \Delta s_{t}$ the annual growth rate of the unobservable supplied quantity of loans during period $t$. As in section 1 , residuals $\mu_{1, t}$ and $\mu_{2, t}$ are assumed stationary and independently and normally distributed. The above model is to be considered as a regime-switching model that allows for two regimes for characterizing $\Delta q_{t}$. Given equation (21), the growth rate of the amount of loans exchanged in the market corresponds to the minimum of the loan supply and demand growth rates. In other words, a demand (supply) regime takes place if the growth rate of the quantity of loans is determined by the variables and their parameters associated with the annual increase in loan demand (supply). The occurrence of regimes, i.e. any divergence between $\Delta d_{t}$ and $\Delta s_{t}$, indicates the existence of a disequilibrium in level in the loan market. Indeed, if the level of demand is equal to the level of supply at each date (i.e. $d_{t}=s_{t}$ ), the annual growth rate of loan demand equals that of loan supply (i.e. $\Delta d_{t}=\Delta s_{t}$ ). However, since the quantity of loans and thereby the estimates of the unobservable loan demand and supply variables are defined here as annual growth rates, our methodology precludes the identification of the type of disequilibrium in level form (whether the level of loan demand exceeds the level of loan supply or vice versa). Hence, with this "min" model on stationary data we have only an approximation of the dynamic of $\Delta q_{t}$ if the disequilibrium model $q_{t}=\min \left(d_{t}, s_{t}\right)$ is the true DGP.

The results for all models are reported in Table (3).

Insert Table 3

Starting with model 1, the coefficients of the total deposits $\left(D E P_{t}\right)$ and of the proxy for firms' cash flow $\left(S A V_{t}\right)$ appear significant and have the expected signs. Moreover, 
Figure 4: Estimated Probabilities of Each Regime, III/94 - II/02

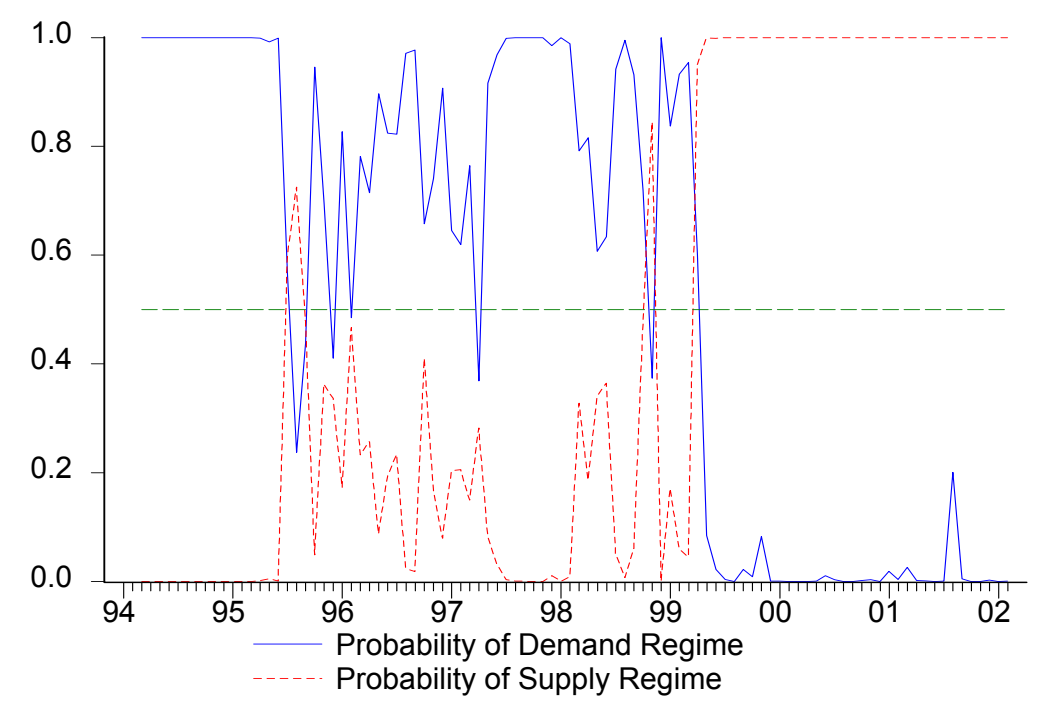

the adjusted R-squared statistics is not as high as in the level form specification of the model (0.41 versus 0.991$)$ and, more importantly, the frequency of the supply regime amounts to only 34 per cent as compared with 82 per cent obtained previously. In model 2, the result of introducing the interest rates is mixed: they are significant and have well-signed coefficients only in the demand equation. Yet, the other variables are still significant, in particular the industrial production $\left(P R O D_{t}\right)$, which has a positively signed coefficient. Finally, although the quality of the model increased in comparison with model 1 , it is nevertheless still fairly low in terms of $\bar{R}^{2}$ statistics. The quality of the model is improved when the imperfect substitutability between loans and riskless assets $\left(A T B_{t}\right)$ on the supply side is taken into account, and by integrating the other forms of credit $\left(O L_{t}\right)$ on the demand side. Indeed, in model 3 there is a net increase in the values of the log-likelihood and in the adjusted R-squared statistics. In addition, all the estimated parameters in both functions have the expected signs and, excepted the interest rates in the loan supply function, are significant. As attested by model 4 estimates, these findings are robust to the introduction of two extra variables reflecting some open economy aspects, i.e. changes in import prices $\left(I M P_{t}\right)$ and the net liquidity impact of the foreign reserves accumulation by the central bank $\left(L N F A_{t}\right)$. As for the level form estimates, we checked in model 5 that our results are not affected by the existing collinearity between the interest rates. Finally, with a one lag structure on the interest rates (cf. model 6), all coefficients have the expected signs and are statistically significant.

Figure (4) plots the estimated probabilities of demand and supply regimes issued from model 6 and Figure (5) plots the corresponding supply and demand growth rates of quantities.

These results corroborate with what one could expect on the Polish credit market. 
Figure 5: Estimated Demand and Supply Growth Rates, III/94 - II/02

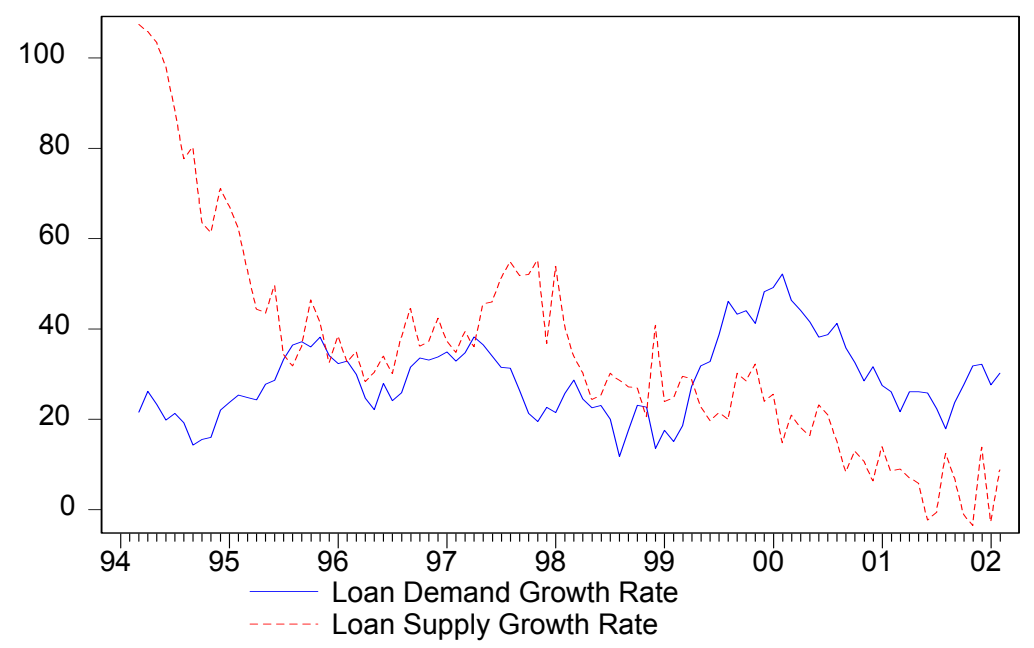

A long-lasting period of a demand regime until mid-1999 and an unambiguous apparition of a supply regime since then. Both regimes match well with several stylized facts related to the Polish loan market. Let us first consider the demand regime. Its occurrence actually coexists with the period of capital inflows under the fixed exchange rate regime. This led to an accumulation of foreign reserves by the central bank, particularly strong between 1995 and 1998 (see Table (4)). Yet, since these capital inflows were imperfectly sterilized, they fueled a boom in the credit market. At the same time, the performance and the health of the banking system improved considerably. As shown in Table (4), banks' profitability was raising until 1996 and remained high in 1997, whereas the percentage of non-performing loans was steadily declining until 1998, thus increasing the quality of the loan portfolio. Table (4) also provides some clues for the switch of the market into a supply regime. The supply conditions deteriorated tremendously at the end of the 1990s: non-performing loans started to rise in 1999 while the gross profit to income ratio has dramatically decreased since 1998.

\section{Insert Table 4}

It should be stressed that while using the "min" condition with stationary data yields robust empirical results, it lacks theoretical foundations. The problem is that the voluntary exchange principle, underlying the model, can only be verified when data in levels are used. However, the fundamental conclusion is that if the spurious regression representation is valid, the disequilibrium has to be identified with stationary components of the observable data used. Moreover, this representation is highly probable when the models of the demand and supply quantities are under-specified. The lower is the number of non-stationary explicative variables in each regime, the higher is the probability to get such a problem and to have a fallacious identification of regimes. 


\section{Conclusion}

The Polish credit market conditions changed dramatically during the 1990s and the clearing of the market was not completely secured by the adjustments of interest rates. The objective of our paper is to confirm econometrically the switch observed in the Polish loan market and to test the disequilibrium hypothesis. For this reason, we apply the standard $M L$ methods on the disequilibrium model with a "min" condition. However, the results are very counter-intuitive, in particular as regards the identification of the regimes in the 1994:02-2002:02 period. It seems that, in our case, the implementation of this technique does not allow to identify the type of disequilibrium a priori expected on the Polish loan market.

We propose an explanation of these counter-intuitive results based on the nonstationarity of the data used. We show that all observed variables are issued from non-stationary processes and are not cointegrated in the corresponding linear models. The issue in the disequilibrium model is that it is impossible to test the cointegration hypothesis in demand and supply equations since demand and supply quantities are unobservable. But, even though there is a cointegration relationship between quantities and a given set of explanatory non-stationary variables, a simple specification error can lead to a configuration with non-stationary residual in at least one equation. That is why we assume that residuals in demand and supply equations may be nonstationary. In this case (spurious regression representation), using wrongly the standard log-likelihood function (Maddala and Nelson, 1974) may lead to non-convergent estimates of the deep parameters and to a fallacious identification of demand and supply regimes.

In order to asses this proposition, we estimate the disequilibrium model with stationary data in first differences. In a first approximation of the transition rule, we use the "min" condition on the annual growth rates. This approximation does not reflect the exact dynamic of the growth rate of the observed loan quantities. However, it allows us to confirm our interpretation of the results obtained for Poland when using variables in levels. We show that the use of stationary data with an approximation of the transition rule leads to a very precise identification of regimes on the Polish credit market in the 1990s. Hence, the determination of the appropriate $M L$ estimation method in the spurious regression representation is the next goal in our research program. 


\section{References}

[1] Bernanke B.S., Blinder A. (1988), "Credit, Money, and Aggregate Demand", American Economic Review Papers and Proceedings, 78, No. 2, May, pp. 435-439.

[2] Bofinger P., Wollmershäuser T. (2002), "Managed Floating: Theory, Practice and ERM II", mimeo, University of Würzburg, 56 p.

[3] Dale S., Haldane A. (1995), "Interest Rates and the Channels of Monetary Transmission: Some Sectoral Estimates", European Economic Review, 39, No. 9, December, pp. 1611-1626.

[4] Fair R.C., Jaffee D.M. (1972), "Methods of Estimation for Markets in Disequilibrium", Econometrica, 40, No. 3, May, pp. 497-514.

[5] Gertler M., Gilchrist S. (1993), "The Role of Credit Market Imperfections in the Monetary Transmission Mechanism: Arguments and Evidence", Scandinavian Journal of Economics, 95, No. 1, pp. 43-64.

[6] IMF (2002), "Republic of Poland: Selected Issues and Statistical Appendix", IMF Country Report, No.02/128, June, 40 p.

[7] Kim H.E. (1999), "Was Credit Channel a Key Monetary Transmission Mechanism Following the Recent Financial Crisis in the Republic of Korea ?", World Bank Policy Research Working Paper, April, No. 3003, 31 p.

[8] Laroque G., Salanié B. (1997), "Normal Estimators for Cointegrating Relationships", Economics Letters, 55, No. 2, August, pp. 185-189.

[9] Maddala G.S., Nelson F.D. (1974), "Maximum Likelihood Methods for Models of Markets in Disequilibrium", Econometrica, 42, No. 6, November, pp. 1013-1030.

[10] OECD (2000), "Poland", OECD Economic Surveys, January, 199 p.

[11] OECD (2001), "Poland", OECD Economic Surveys, April, 175 p.

[12] Opiela T.P. (1999), "The Responsiveness of Loan Rates to Monetary Policy in Poland: The Effects of Bank Structure", National Bank of Poland Working Paper Series, No. 17, December, 43 p.

[13] PazarbaşıoĞLu C. (1997), "A Credit Crunch ? Finland in the Aftermath of the Banking Crisis", IMF Staff Papers, 44, No. 3, September, pp. 315-327.

[14] Perez S.J. (1998), "Testing for Credit Rationing: An Application of Disequilibrium Econometrics", Journal of Macroeconomics, 20, No. 4, Fall, pp. 721-739.

[15] Sealey C.W. (1979), "Credit Rationing in the Commercial Loan Market: Estimates of a Structural Model under Conditions of Disequilibrium", The Journal of Finance, 34, No. 3, June, pp. 689-702. 


\section{A Appendix}

\section{A.1 Marginal densities of $Q_{t}$ in a stable disequilibrium model}

Let us denote $g_{D_{t}, S_{t}}\left(d_{t}, s_{t}\right)$ the joint density of $D_{t}$ and $S_{t}$. We know that the corresponding marginal densities of the unobservable variables $D_{t}$ and $S_{t}$ are defined by:

$$
f_{D_{t}}\left(d_{t}\right)=\int_{-\infty}^{\infty} g_{D_{t}, S_{t}}\left(d_{t}, z\right) d z \quad f_{S_{t}}\left(s_{t}\right)=\int_{-\infty}^{\infty} g_{D_{t}, S_{t}}\left(z, s_{t}\right) d z
$$

We have to compute the marginal density of $Q_{t}$ on the two subset $Q_{t}=D_{t}$, with $D_{t}<S_{t}$ and $Q_{t}=S_{t}$, with $S_{t}<D_{t}$. When $D_{t}<S_{t}$, for a given realization $d_{t}$ of $D_{t}$, the marginal density of $Q_{t}$, is given by the area defined by the joint density $g_{D_{t}, S_{t}}\left(d_{t}, z\right)$, for values $z$ of $S_{t}$ superior to $d_{t}$. Under the assumption that $D_{t}<S_{t}$, the marginal density of $Q_{t}$ is then given by:

$$
f_{Q_{t} \mid D_{t}<S_{t}}\left(q_{t}\right)=\int_{q_{t}=d_{t}}^{\infty} g_{D_{t}, S_{t}}\left(d_{t}, z\right) d z
$$

Symmetrically, we get the marginal density of $Q_{t}$ when $S_{t}<D_{t}$.

$$
f_{Q_{t} \mid S_{t}<D_{t}}\left(q_{t}\right)=\int_{q_{t}=s_{t}}^{\infty} g_{D_{t}, S_{t}}\left(z, s_{t}\right) d z
$$

In the general case, we know that the marginal density of $Q_{t}$ is given by:

$$
f_{Q_{t}}\left(q_{t}\right)=\int_{q_{t}}^{\infty} g_{D_{t}, S_{t}}\left(q_{t}, z\right) d z+\int_{q_{t}}^{\infty} g_{D_{t}, S_{t}}\left(z, q_{t}\right) d z
$$

Let us assume that both residuals $\varepsilon_{1}$ and $\varepsilon_{2}$ are independent $\left(\sigma_{12}=0\right)$. In this case, the joint density can be expressed as the following simple expression:

$$
\begin{aligned}
g_{D_{t}, S_{t}}\left(d_{t}, s_{t}\right) & =\frac{1}{2 \pi \sigma_{1} \sigma_{2}} \exp \left\{-\frac{1}{2}\left[\left(\frac{d_{t}-x_{1, t}^{\prime} \beta_{1}}{\sigma_{1}}\right)^{2}+\left(\frac{s_{t}-x_{2, t}^{\prime} \beta_{2}}{\sigma_{2}}\right)^{2}\right]\right\} \\
& =\frac{1}{2 \pi \sigma_{1} \sigma_{2}} \exp \left[-\frac{1}{2}\left(\frac{d_{t}-x_{1, t}^{\prime} \beta_{1}}{\sigma_{1}}\right)^{2}\right] \times \exp \left[-\frac{1}{2}\left(\frac{s_{t}-x_{2, t}^{\prime} \beta_{2}}{\sigma_{2}}\right)^{2}\right]
\end{aligned}
$$

Now, consider the first member of the marginal density of $Q_{t}$ (equation (25)):

$$
\begin{aligned}
& \int_{q_{t}}^{\infty} g_{D_{t}, S_{t}}\left(q_{t}, z\right) d z=\frac{1}{2 \pi \sigma_{1} \sigma_{2}} \int_{q_{t}}^{\infty}\left\{\exp \left[-\frac{1}{2}\left(\frac{q_{t}-x_{1, t}^{\prime} \beta_{1}}{\sigma_{1}}\right)^{2}\right] \times \exp \left[-\frac{1}{2}\left(\frac{z-x_{2, t}^{\prime} \beta_{2}}{\sigma_{2}}\right)^{2}\right]\right\} d z \\
= & \frac{1}{\sqrt{2 \pi} \sigma_{1}} \exp \left[-\frac{1}{2}\left(\frac{q_{t}-x_{1, t}^{\prime} \beta_{1}}{\sigma_{1}}\right)^{2}\right] \times \frac{1}{\sqrt{2 \pi} \sigma_{2}} \int_{q_{t}}^{\infty} \exp \left[-\frac{1}{2}\left(\frac{z-x_{2, t}^{\prime} \beta_{2}}{\sigma_{2}}\right)^{2}\right] d z
\end{aligned}
$$

In the first term of this expression, we recognize the value of the $N(0,1)$ density function at the particular point $\left(q_{t}-x_{1, t}^{\prime} \beta_{1}\right) / \sigma_{1}$. Indeed:

$$
\frac{1}{\sqrt{2 \pi}} \exp \left[-\frac{1}{2}\left(\frac{q_{t}-x_{1, t}^{\prime} \beta_{1}}{\sigma_{1}}\right)^{2}\right]=\phi\left(\frac{q_{t}-x_{1, t}^{\prime} \beta_{1}}{\sigma_{1}}\right)
$$


where $\phi($.$) denotes the N(0,1)$ density function. Since this function is symmetric the first member of the marginal density of $Q_{t}$ can be expressed as:

$$
\int_{q_{t}}^{\infty} g_{D_{t}, S_{t}}\left(q_{t}, z\right) d z=\frac{1}{\sigma_{1}} \phi\left(\frac{x_{1, t}^{\prime} \beta_{1}-q_{t}}{\sigma_{1}}\right) \times \frac{1}{\sqrt{2 \pi} \sigma_{2}} \int_{q_{t}}^{\infty} \exp \left[-\frac{1}{2}\left(\frac{z-x_{2, t}^{\prime} \beta_{2}}{\sigma_{2}}\right)^{2}\right] d z
$$

The second term of this expression can be transformed in order to introduce the $N(0,1)$ cumulative distribution function, denoted $\Phi($.$) . Indeed, let us consider the following$ change in variable $\widetilde{z}=\left(z-x_{2, t}^{\prime} \beta_{2}\right) / \sigma_{2}$, with $d z=d \widetilde{z} \sigma_{2}$. Then, we have:

$$
\begin{aligned}
\frac{1}{\sqrt{2 \pi} \sigma_{2}} \int_{q_{t}}^{\infty} \exp \left[-\frac{1}{2}\left(\frac{z-x_{2, t}^{\prime} \beta_{2}}{\sigma_{2}}\right)^{2}\right] d z & =\frac{1}{\sqrt{2 \pi} \sigma_{2}} \int_{\widetilde{q}_{t}}^{\infty} \exp \left(-\frac{\widetilde{z}^{2}}{2}\right) d \widetilde{z} \sigma_{2} \\
& =\frac{1}{\sqrt{2 \pi}} \int_{\widetilde{q_{t}}}^{\infty} \exp \left(-\frac{\widetilde{z}^{2}}{2}\right) d \widetilde{z}
\end{aligned}
$$

with $\widetilde{q}_{t}=\left(q_{t}-x_{2, t}^{\prime} \beta_{2}\right) / \sigma_{2}$. Then, this integral can be expressed as a function $\Phi($.$) .$

$$
\frac{1}{\sqrt{2 \pi} \sigma_{2}} \int_{q_{t}}^{\infty} \exp \left[-\frac{1}{2}\left(\frac{z-x_{2, t}^{\prime} \beta_{2}}{\sigma_{2}}\right)^{2}\right] d z=1-\Phi\left(\widetilde{q}_{t}\right)=\Phi\left(-\widetilde{q}_{t}\right)
$$

Finally, we get:

$$
\int_{q_{t}}^{\infty} g_{D_{t}, S_{t}}\left(q_{t}, z\right) d z=\frac{1}{\sigma_{1}} \phi\left(\frac{x_{1, t}^{\prime} \beta_{1}-q_{t}}{\sigma_{1}}\right) \Phi\left(\frac{x_{2, t}^{\prime} \beta_{2}-q_{t}}{\sigma_{2}}\right)
$$

Symmetrically, we can compute the second term of the marginal density of $Q_{t}$ (equation (25)) as:

$$
\int_{q_{t}}^{\infty} g_{D_{t}, S_{t}}\left(z, q_{t}\right) d z=\frac{1}{\sigma_{2}} \phi\left(\frac{x_{2, t}^{\prime} \beta_{2}-q_{t}}{\sigma_{2}}\right) \Phi\left(\frac{x_{1, t}^{\prime} \beta_{1}-q_{t}}{\sigma_{1}}\right)
$$

Then, the marginal density of $Q_{t}$ is defined by equation (10):

$$
\begin{aligned}
f_{Q_{t}}\left(q_{t}\right)= & \frac{1}{\sigma_{1}} \phi\left(\frac{x_{1, t}^{\prime} \beta_{1}-q_{t}}{\sigma_{1}}\right) \Phi\left(\frac{x_{2, t}^{\prime} \beta_{2}-q_{t}}{\sigma_{2}}\right) \\
& +\frac{1}{\sigma_{2}} \phi\left(\frac{x_{2, t}^{\prime} \beta_{2}-q_{t}}{\sigma_{2}}\right) \Phi\left(\frac{x_{1, t}^{\prime} \beta_{1}-q_{t}}{\sigma_{1}}\right)
\end{aligned}
$$

\section{A.2 The choice of initial condition in the $M L$ optimization procedure}

There are various methods to obtain the initial conditions on structural parameters $\theta$ in the $M L$ iteration. Here, we use a two step $O L S$ procedure. First, we consider the linear regressions of the observation $q_{t}$ on the exogenous variables sets in both functions: $q_{t}=x_{i, t}^{\prime} \widehat{\gamma}_{i}+\mu_{i, t}$, with $i=1,2$. Given the realizations of $\widehat{\gamma}_{1}$ and $\widehat{\gamma}_{2}$, we compute a first approximation of demand and supply, as $\widetilde{d}_{t}=x_{1, t}^{\prime} \widehat{\gamma}_{1}$ and $\widetilde{s}_{t}=x_{2, t}^{\prime} \widehat{\gamma}_{2}$. Even if we know that $\widehat{\gamma}_{1}$ and $\widehat{\gamma}_{2}$ are not convergent estimators of $\beta_{1}$ and $\beta_{2}$, we build 
two subgroups of observations. In the first subgroup, denoted by index $d$, we consider only the observations on $Q_{t}, X_{1, t}$ and $X_{2, t}$ for which we have $\widetilde{d}_{t} \leq \widetilde{s}_{t}$. In the second subgroup, we consider the observations for which we have $\widetilde{s}_{t} \leq \widetilde{d}_{t}$. The second step of the procedure consists in applying the $O L S$ on both subgroups:

$$
q_{t}^{(d)}=x_{1, t}^{(d) \prime} \widetilde{\beta}_{1}+\widetilde{\mu}_{1, t} \text { and } q_{t}^{(s)}=x_{2, t}^{(s) \prime} \widetilde{\beta}_{2}+\widetilde{\mu}_{2, t}
$$

Then, we use the $O L S$ estimates $\widetilde{\beta}_{i}$ as starting values for $\beta_{i}$ in the $M L$ iteration. For the parameters $\sigma_{1}$ and $\sigma_{2}$, we adopt the following starting values:

$$
\widetilde{\sigma}_{i}=\frac{1}{n_{i}} \sum_{j=1}^{n_{i}} \widetilde{\mu}_{i, j} \quad i=1,2
$$

where $n_{1}$ denotes the size of the "demand" subgroup of observations for which we have $\widetilde{d}_{t} \leq \widetilde{s}_{t}$, and $n_{2}$ denotes the size of the corresponding "supply" subgroup. Some Monte Carlo simulations of the accuracy of this procedure are disposable on request.

\section{A.3 Unit root and cointegration tests}

The results of the unit root and cointegration tests are reported in Tables 5 and 6 .

Insert Table 5

Insert Table 6 
William Davidson Institute Working Paper 581

Table 1: ML Estimates in Level, II/94 - II/02

\begin{tabular}{|c|c|c|c|c|c|c|}
\hline & Model 1 & Model 2 & Model 3 & Model 4 & Model 5 & 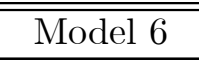 \\
\hline Supply & \multirow{7}{*}{$\begin{array}{l}-0.21^{* *} \\
(-4.00)\end{array}$} & & & & & \\
\hline Constant & & $\begin{array}{c}-0.65^{* *} \\
(-3.24)\end{array}$ & $\begin{array}{l}0.78^{*} \\
(1.66)\end{array}$ & $\begin{array}{l}0.32 \\
(0.74)\end{array}$ & $\begin{array}{l}0.32 \\
(0.74)\end{array}$ & $\begin{array}{l}0.49 \\
(1.57)\end{array}$ \\
\hline$I L_{t}$ & & $\begin{array}{c}0.004^{* *} \\
(2.57)\end{array}$ & $\underset{(-1.51)}{-\mathbf{0 . 0 0 3}}$ & $-\underset{(-0.13)}{\mathbf{0 . 0 0 0 3}}$ & & \\
\hline$I C_{t}$ & & \multirow{4}{*}{$\begin{array}{l}-0.002 \\
(-1.48)\end{array}$} & \multirow[t]{4}{*}{$\mathbf{0 . 0 0 3}_{(1.71)}^{*}$} & \multirow[t]{4}{*}{$\begin{array}{c}-0.0002 \\
(-0.11)\end{array}$} & \multirow{3}{*}{$\begin{array}{c}-0.0005 \\
(-0.39)\end{array}$} & \\
\hline$I L_{t-1}$ & & & & & & $\underset{(-0.17)}{-\mathbf{0 . 0 0 0 3}}$ \\
\hline$I C_{t-1}$ & & & & & & $\begin{array}{c}-0.001 \\
(-1.07)\end{array}$ \\
\hline$(I L-I C)_{t}$ & & & & & $\begin{array}{c}-0.0003 \\
(-0.13)\end{array}$ & \\
\hline$D E P_{t}$ & \multirow[t]{3}{*}{$\begin{array}{l}0.90^{* *} \\
(82.85)\end{array}$} & \multirow[t]{3}{*}{$\begin{array}{c}0.98^{* *} \\
(27.62)\end{array}$} & \multirow{3}{*}{$\begin{array}{c}0.77^{* *} \\
(11.29) \\
-0.27^{* *} \\
(-3.28)\end{array}$} & $\begin{array}{c}0.77^{* *} \\
(11.81)\end{array}$ & $\begin{array}{c}0.77^{* *} \\
(11.81)\end{array}$ & $\begin{array}{c}0.73^{* *} \\
(15.91)\end{array}$ \\
\hline$A T B_{t}$ & & & & $\begin{array}{l}-0.19^{* *} \\
(-2.56)\end{array}$ & $\begin{array}{c}-0.19^{* *} \\
(-2.56)\end{array}$ & $\begin{array}{c}-0.16^{* *} \\
(-3.01)\end{array}$ \\
\hline$L N F A_{t}$ & & & & $\begin{array}{c}0.17^{* *} \\
(3.47)\end{array}$ & $\begin{array}{c}0.17^{* *} \\
(3.47)\end{array}$ & $\begin{array}{c}0.17^{* *} \\
(4.06)\end{array}$ \\
\hline$\sigma_{1}$ & 0.021 & 0.019 & 0.019 & 0.016 & 0.016 & 0.015 \\
\hline \multicolumn{7}{|l|}{ Demand } \\
\hline Constant & \multirow[t]{7}{*}{$\begin{array}{l}3.65^{* *} \\
(14.44)\end{array}$} & $\begin{array}{l}3.46^{* *} \\
(7.44)\end{array}$ & $\begin{array}{l}5.86^{* *} \\
(6.12)\end{array}$ & $\begin{array}{l}2.88^{* *} \\
(3.05)\end{array}$ & $\begin{array}{c}2.88^{* *} \\
(3.04)\end{array}$ & $\begin{array}{c}5.40^{* *} \\
(6.82)\end{array}$ \\
\hline$I L_{t}$ & & $\begin{array}{c}-0.02^{* *} \\
(-5.98)\end{array}$ & $\begin{array}{c}-0.001 \\
(-0.31)\end{array}$ & $\begin{array}{l}-0.006^{*} \\
(-1.77)\end{array}$ & & \\
\hline$I C_{t}$ & & \multirow[t]{4}{*}{$\begin{array}{l}0.02^{* *} \\
(6.11)\end{array}$} & \multirow[t]{4}{*}{$\frac{-\mathbf{0 . 0 0 0}}{(-0.005)}$} & \multirow[t]{4}{*}{$\begin{array}{l}0.003 \\
(1.31)\end{array}$} & \multirow[t]{3}{*}{$\begin{array}{l}-0.002 \\
(-1.53)\end{array}$} & \\
\hline$I L_{t-1}$ & & & & & & $\begin{array}{c}-0.02^{* *} \\
(-8.35)\end{array}$ \\
\hline$I C_{t-1}$ & & & & & & $\begin{array}{c}0.01^{* *} \\
(7.95)\end{array}$ \\
\hline$(I L-I C)_{t}$ & & & & & $\begin{array}{c}-0.006^{*} \\
(-1.77)\end{array}$ & \\
\hline $\mathrm{PROD}_{t}$ & & $\begin{array}{l}-0.09 \\
(-0.71)\end{array}$ & $\begin{array}{l}-0.02 \\
(-0.26)\end{array}$ & $\begin{array}{l}-0.03 \\
(-0.27)\end{array}$ & $\begin{array}{l}-0.03 \\
(-0.27)\end{array}$ & $\begin{array}{l}0.12^{* *} \\
(2.24)\end{array}$ \\
\hline$S A V_{t}$ & \multirow[t]{3}{*}{$\underset{(3.71)}{\mathbf{0 . 2 1}}$} & \multirow[t]{3}{*}{$\underset{(4.23)}{\mathbf{0 . 3 9}}$} & \multirow{3}{*}{$\begin{array}{c}\mathbf{0 . 6 5}^{* *} \\
(9.88) \\
-2.20^{* *} \\
(-4.14)\end{array}$} & $\begin{array}{c}\mathbf{0 . 5 1} \mathbf{1}^{* *} \\
(7.77)\end{array}$ & $\begin{array}{c}\mathbf{0 . 5 1} 1^{* *} \\
(7.75)\end{array}$ & $\mathbf{0 . 2 8}_{(4.36)}^{\mathbf{0 . 2 *}}$ \\
\hline$O L_{t}$ & & & & $\begin{array}{c}-0.99^{* *} \\
(-2.24)\end{array}$ & $\begin{array}{c}-0.99^{* *} \\
(-2.24)\end{array}$ & $\begin{array}{l}-1.80^{* *} \\
(-5.20)\end{array}$ \\
\hline$I M P_{t}$ & & & & $\begin{array}{c}0.61^{* *} \\
(3.41)\end{array}$ & $\begin{array}{c}0.61^{* *} \\
(3.40)\end{array}$ & $\begin{array}{c}0.34^{* *} \\
(3.45)\end{array}$ \\
\hline \multirow[t]{7}{*}{$\sigma_{2}$} & 0.008 & 0.013 & 0.010 & 0.010 & 0.010 & 0.003 \\
\hline & $L=254.77$ & $L=256.62$ & $L=271.20$ & $L=282.15$ & $L=282.15$ & $L=287.80$ \\
\hline & $\bar{R}^{2}=0.991$ & $\bar{R}^{2}=0.992$ & $\bar{R}^{2}=0.993$ & $\bar{R}^{2}=0.994$ & $\bar{R}^{2}=0.994$ & $\bar{R}^{2}=0.994$ \\
\hline & $n_{S}=77$ & $n_{S}=66$ & $n_{S}=66$ & $n_{S}=67$ & $n_{S}=67$ & $n_{S}=79$ \\
\hline & $n_{D}=17$ & $n_{D}=26$ & $n_{D}=30$ & $n_{D}=30$ & $n_{D}=30$ & $n_{D}=16$ \\
\hline & $F_{S}=82 \%$ & $F_{S}=72 \%$ & $F_{S}=69 \%$ & $F_{S}=69 \%$ & $F_{S}=69 \%$ & $F_{S}=83 \%$ \\
\hline & $F_{D}=18 \%$ & $F_{D}=28 \%$ & $F_{D}=31 \%$ & $F_{D}=31 \%$ & $F_{D}=31 \%$ & $F_{D}=17 \%$ \\
\hline
\end{tabular}

Source: Authors' calculations.

Notes: (1) Asymptotic t-statistics are in parentheses, L: log-likelihood. (2)*(**) denotes significance at $10 \%(5 \%)$ level.

(3) Bold characters are for variables which do not have the expected sign coefficient. (4) nD (nS) denotes the number

of demand (supply) periods, and FD (FS) denotes the frequency of supply (demand) regimes given that a period or regime

occurs when the corresponding probability is higher than 0.5 . 
Table 2: Credit to the Corporate Sector to GDP Ratio, 1989 - 1999

\begin{tabular}{ccccccccccc}
\hline \hline 1989 & 1990 & 1991 & 1992 & 1993 & 1994 & 1995 & 1996 & 1997 & 1998 & 1999 \\
\hline 28.3 & 21.1 & 23 & 20.6 & 19.9 & 17.1 & 16.4 & 17.6 & 18.6 & 19.8 & 21.2 \\
\hline
\end{tabular}

Source: National Bank of Poland and the authors' calculations. 
William Davidson Institute Working Paper 581

Table 3: ML Estimates in Growth Rates, II/94 - II/02

\begin{tabular}{|c|c|c|c|c|c|c|}
\hline & Model 1 & Model 2 & Model 3 & Model 4 & Model 5 & Model 6 \\
\hline$\Delta$ Supply & \multirow{7}{*}{$\begin{array}{c}-11.69 \\
(-1.25)\end{array}$} & & & & & \\
\hline Constant & & $\begin{array}{l}7.85 \\
(0.37)\end{array}$ & $\begin{array}{l}-1.54 \\
(-0.09)\end{array}$ & $\begin{array}{l}-6.29 \\
(-0.32)\end{array}$ & $\begin{array}{l}-6.29 \\
(-0.32)\end{array}$ & $\begin{array}{c}-30.77^{* *} \\
(-2.46)\end{array}$ \\
\hline$I L_{t}$ & & $\begin{array}{c}-\mathbf{3 . 0 9} \\
(-0.95)\end{array}$ & $\begin{array}{l}0.72 \\
(0.30)\end{array}$ & $\begin{array}{l}1.74 \\
(0.51)\end{array}$ & & \\
\hline$I C_{t}$ & & $\begin{array}{l}\mathbf{1 . 9 2} \\
(0.68)\end{array}$ & $\begin{array}{l}-1.80 \\
(-0.96)\end{array}$ & $\begin{array}{l}-2.99 \\
(-1.01)\end{array}$ & $\begin{array}{l}-1.25 \\
(-1.19)\end{array}$ & \\
\hline$I L_{t-1}$ & & & & & & $\underset{(2.83)}{7.10^{* *}}$ \\
\hline & & & & & & $\begin{array}{c}-7.20^{* *} \\
(-3.16)\end{array}$ \\
\hline$(I L-I C)_{t}$ & & & \multirow{4}{*}{$\begin{array}{c}1.74^{* *} \\
(4.03) \\
-0.44^{* *} \\
(-3.67)\end{array}$} & & $\begin{array}{l}1.73 \\
(0.51)\end{array}$ & \\
\hline$\Delta D E P_{t}$ & \multirow{3}{*}{$\begin{array}{l}1.63^{* *} \\
(2.95)\end{array}$} & \multirow[t]{3}{*}{$\begin{array}{l}2.12^{* *} \\
(2.45)\end{array}$} & & $\begin{array}{c}1.94^{* *} \\
(4.03)\end{array}$ & $\begin{array}{c}1.94^{* *} \\
(4.03)\end{array}$ & $\begin{array}{c}1.37^{* *} \\
(7.10)\end{array}$ \\
\hline$\Delta A T B_{t}$ & & & & $\begin{array}{c}-0.44^{* *} \\
(-2.95)\end{array}$ & $\begin{array}{c}-0.44^{* *} \\
(-2.95)\end{array}$ & $\begin{array}{c}-0.56^{* *} \\
(-5.26)\end{array}$ \\
\hline$\Delta L N F A_{t}$ & & & & $\begin{array}{l}0.31^{* *} \\
(3.40)\end{array}$ & $\begin{array}{l}0.31^{* *} \\
(3.40)\end{array}$ & $\begin{array}{c}0.33^{* *} \\
(4.21)\end{array}$ \\
\hline$\sigma_{1}$ & 10.62 & 10.42 & 7.57 & 7.05 & 7.05 & 5.87 \\
\hline$\Delta$ Demand & \multirow{8}{*}{$\begin{array}{c}37.13^{* *} \\
(13.38)\end{array}$} & \multirow{7}{*}{$\begin{array}{c}40.55^{* *} \\
(4.42) \\
-1.32^{* *} \\
(-2.64) \\
1.07 \\
(1.52)\end{array}$} & \multirow{7}{*}{$\begin{array}{c}38.97^{* *} \\
(6.04) \\
-1.40^{* *} \\
(-4.96) \\
1.78^{* *} \\
(4.06)\end{array}$} & \multirow{7}{*}{$\begin{array}{c}33.56^{* *} \\
(7.64) \\
-1.40^{* *} \\
(-4.41) \\
1.73^{* *} \\
(4.16)\end{array}$} & \multirow{3}{*}{$\underset{(7.64)}{33.56^{* *}}$} & \multirow{4}{*}{$\begin{array}{c}49.87^{* *} \\
(10.07)\end{array}$} \\
\hline Constant & & & & & & \\
\hline$I L_{t}$ & & & & & & \\
\hline$I C_{t}$ & & & & & $\begin{array}{l}0.32 \\
(1.27)\end{array}$ & \\
\hline$I L_{t-1}$ & & & & & & $\begin{array}{c}-1.38^{* *} \\
(-4.24)\end{array}$ \\
\hline$I C_{t-1}$ & & & & & & $0.92^{* *}$ \\
\hline$(I L-I C)_{t}$ & & & & & $\begin{array}{l}-1.40^{* *} \\
(-4.41)\end{array}$ & \\
\hline$\triangle P R O D_{t}$ & & $\begin{array}{c}0.34^{* *} \\
(2.53)\end{array}$ & $\begin{array}{l}0.04 \\
(0.37)\end{array}$ & $\begin{array}{l}-0.04 \\
(-0.50)\end{array}$ & $\begin{array}{l}-0.04 \\
(-0.50)\end{array}$ & $\begin{array}{l}0.07 \\
(0.89)\end{array}$ \\
\hline$\Delta S A V_{t}$ & \multirow[t]{3}{*}{$\begin{array}{c}-0.29^{* *} \\
(-4.17)\end{array}$} & \multirow[t]{3}{*}{$\begin{array}{c}-0.33^{* *} \\
(-4.31)\end{array}$} & $\begin{array}{c}-0.27^{* *} \\
(-6.49)\end{array}$ & $\begin{array}{c}-0.26^{* *} \\
(-6.95)\end{array}$ & $\begin{array}{c}-0.26^{* *} \\
(-6.95)\end{array}$ & $\begin{array}{c}-0.25^{* *} \\
(-5.90)\end{array}$ \\
\hline$\Delta O L_{t}$ & & & $\begin{array}{c}-2.97^{* *} \\
(-7.45)\end{array}$ & $\begin{array}{c}-1.77^{* *} \\
(-5.45)\end{array}$ & $\begin{array}{c}-1.77^{* *} \\
(-5.45)\end{array}$ & $\begin{array}{c}-2.46^{* *} \\
(-6.75)\end{array}$ \\
\hline$\Delta I M P_{t}$ & & & & $\begin{array}{c}0.27^{* *} \\
(2.85)\end{array}$ & $\begin{array}{c}0.27^{* *} \\
(2.85)\end{array}$ & $\begin{array}{c}0.31^{* *} \\
(3.47)\end{array}$ \\
\hline \multirow[t]{7}{*}{$\sigma_{2}$} & 5.71 & 4.33 & 2.72 & 3.05 & 3.05 & 2.74 \\
\hline & $L=-324.84$ & $L=-308.10$ & $L=-284.95$ & $L=-272.04$ & $L=-272.04$ & $L=-261.72$ \\
\hline & $\bar{R}^{2}=0.41$ & $\bar{R}^{2}=0.47$ & $\bar{R}^{2}=0.63$ & $\bar{R}^{2}=0.73$ & $\bar{R}^{2}=0.73$ & $\bar{R}^{2}=0.80$ \\
\hline & $n_{S}=31$ & $n_{S}=30$ & $n_{S}=53$ & $n_{S}=32$ & $n_{S}=32$ & $n_{S}=38$ \\
\hline & $n_{D}=61$ & $n_{D}=66$ & $n_{D}=43$ & $n_{D}=63$ & $n_{D}=63$ & $n_{D}=56$ \\
\hline & $F_{S}=34 \%$ & $F_{S}=31 \%$ & $F_{S}=55 \%$ & $F_{S}=34 \%$ & $F_{S}=34 \%$ & $F_{S}=40 \%$ \\
\hline & $F_{D}=66 \%$ & $F_{D}=69 \%$ & $F_{D}=45 \%$ & $F_{D}=66 \%$ & $F_{D}=66 \%$ & $F_{D}=60 \%$ \\
\hline
\end{tabular}

Source: Authors' calculations.

Notes: (1) Asymptotic t-statistics are in parentheses, L: log-likelihood. (2)*(**) denotes significance at $10 \%(5 \%)$ level.

(3) Bold characters are for variables which do not have the expected sign coefficient. (4) nD (nS) denotes the number

of demand (supply) periods, and FD (FS) denotes the frequency of supply (demand) regimes given that a period or regime

occurs when the corresponding probability is higher than 0.5 . 
Table 4: Banking Indicators and Gross Official Reserves, 1993 - 2001 (End-of-Year)

\begin{tabular}{lccccccccc}
\hline \hline & 1993 & 1994 & 1995 & 1996 & 1997 & 1998 & 1999 & 2000 & 2001 \\
Gross profit/income (in per cent) & 6.0 & 6.0 & 16.9 & 19.4 & 14.7 & 7.1 & 6.2 & 4.6 & 2.6 \\
$\begin{array}{l}\text { Non-performing loans } \\
\text { (in per cent of total loan portfolio) }\end{array}$ & 31.0 & 28.7 & 20.9 & 13.2 & 10.5 & 10.9 & 13.7 & 15.5 & 18.3 \\
$\begin{array}{l}\text { Gross official reserves } \\
\text { (stock, UsD billion) }\end{array}$ & 4.3 & 6.0 & 15.0 & 18.0 & 20.7 & 28.3 & 27.3 & 27.5 & 26.6 \\
\hline
\end{tabular}

Table 5: Augmented Dickey-Fuller and Phillips-Perron Tests: Variables in Level Forms, II $/ 94$ - II/02

\begin{tabular}{c|cccc|cc||c|c}
\hline \hline & \multicolumn{7}{|c||}{ ADF Statistics } & \multicolumn{2}{c}{ PP Statistics } \\
\hline Variable & $\begin{array}{c}\text { Numb. } \\
\text { of Lags }\end{array}$ & $\begin{array}{c}\text { UR with } \\
\text { Const. }\end{array}$ & $\begin{array}{c}\text { Joint Test: UR } \\
\text { and no Const. }\end{array}$ & $\begin{array}{c}\text { T-Statistic } \\
\text { on the Const. }\end{array}$ & $\begin{array}{c}\text { Numb. } \\
\text { of Lags }\end{array}$ & $\begin{array}{c}\text { UR without } \\
\text { Const. }\end{array}$ & $\begin{array}{c}\text { UR } \\
\text { with Const. }\end{array}$ & $\begin{array}{c}\text { UR } \\
\text { without Const. }\end{array}$ \\
\hline$I L$ & 1 & -1.93 & $4.33^{*}$ & - & 1 & $-2.63^{* *}$ & -1.89 & $-3.05^{* *}$ \\
$I C$ & 6 & -1.41 & 1.56 & - & 1 & $-1.84^{* *}$ & -0.39 & $-1.73^{*}$ \\
$C R$ & 0 & -2.37 & $24.38^{* *}$ & - & 2 & 3.11 & -2.22 & 5.40 \\
$P R O D$ & 8 & $-3.15^{* *}$ & - & $3.22^{* *}$ & 8 & 1.96 & $-2.93^{* *}$ & 2.24 \\
$D E P$ & 2 & $-5.34^{* *}$ & - & $5.79^{* *}$ & 1 & 7.22 & $-5.27^{* *}$ & 9.58 \\
$S A V$ & 0 & -1.40 & $6.77^{* *}$ & - & 2 & 4.47 & -1.63 & 4.51 \\
$L N F A$ & 0 & -2.48 & 3.36 & - & 1 & 0.74 & -2.16 & 0.94 \\
$I M P$ & 0 & $-2.67^{*}$ & $5.41^{* *}$ & - & 0 & 1.77 & $-3.03^{* *}$ & 2.11 \\
$O L$ & 0 & -1.48 & 1.71 & - & 0 & 1.08 & -1.48 & 1.10 \\
$A T B$ & 0 & -0.63 & 0.57 & - & 0 & -0.91 & -0.61 & -0.94 \\
\hline
\end{tabular}

Source: Authors' calculations.

Notes: $(1)^{*}(* *)$ denotes rejection of the null hypothesis at $10 \%(5 \%)$ level. (2) The optimal lag number for ADF tests

was determined using the Schwarz criterion, and for PP tests acording to the Newey-West criterion, which pointed at 3 lags.

Table 6: Johansen Cointegration Tests Between the Amount of Credit and Exogenous Variables, II/94 - II/02

\begin{tabular}{lcccccc}
\hline \hline & Model 1 & Model 2 & Model 3 & Model 4 & Model 5 & Model 6 \\
$H_{0}$ & $R=0$ & $R=0$ & $R=0$ & $R=0$ & $R=0$ & $R=0$ \\
$\lambda_{\text {trace }}$ & 2.09 & 1.30 & $18.15^{* *}$ & $32.13^{* *}$ & $32.13^{* *}$ & $106.65^{* *}$ \\
Eigenvalue & 0.02 & 0.01 & 0.17 & 0.28 & 0.28 & 0.85 \\
\hline Source: Authors' calculations. \\
Notes: (1) ${ }^{* * *}$ denotes rejection of the null hypothesis at 10\% (5\%) level. (2) Tests allow for an intercept \\
but no trend in the cointegrating relationship.
\end{tabular}




\section{DAVIDSON INSTITUTE WORKING PAPER SERIES - Most Recent Papers}

The entire Working Paper Series may be downloaded free of charge at: www.wdi.bus.umich.edu

CURRENT AS OF 6/17/03

\begin{tabular}{|c|c|c|}
\hline Publication & Authors & Date \\
\hline $\begin{array}{l}\text { No. 581: Credit Market Disequilibrium in Poland: Can We Find } \\
\text { What We Expect? Non-Stationarity and the "Min" } \\
\text { Condition }\end{array}$ & $\begin{array}{l}\text { Christophe Hurlin and Rafal } \\
\text { Kierzenkowski }\end{array}$ & June 2003 \\
\hline $\begin{array}{l}\text { No. 580: Does it Take a Lula to go to Davos? } \\
\text { A Brief Overview of Brazilian Reforms, 1980-2000 }\end{array}$ & $\begin{array}{l}\text { Nauro F. Campos, Armando } \\
\text { Castellar Pinheiro, Fabio } \\
\text { Giambiagi and Maurício M. } \\
\text { Moreira }\end{array}$ & June 2003 \\
\hline $\begin{array}{l}\text { No. 579: Ceaseless Toil? Health and Labor Supply of the Elderly in } \\
\text { Rural China }\end{array}$ & $\begin{array}{l}\text { Dwayne Benjamin, Loren Brandt } \\
\text { and Jia-Zhueng Fan }\end{array}$ & June 2003 \\
\hline $\begin{array}{l}\text { No. 578: Shadow Economy, Rent-Seeking Activities and the Perils of } \\
\text { Reinforcement of the Rule of Law }\end{array}$ & Ekaterina Vostroknutova & June 2003 \\
\hline $\begin{array}{l}\text { No. 577: No Pain, No Gain: Market Reform, Unemployment, and } \\
\text { Politics in Bulgaria }\end{array}$ & Neven Valev & June 2003 \\
\hline $\begin{array}{l}\text { No. 576: Power Analysis of the Nice Treaty On the Future of European } \\
\text { Integration }\end{array}$ & Yener Kandogan & June 2003 \\
\hline $\begin{array}{l}\text { No. 575: Democracy's Spread: Elections and Sovereign Debt in } \\
\text { Developing Countries }\end{array}$ & $\begin{array}{l}\text { Steven A. Block, Burkhard N. } \\
\text { Schrage, and Paul M. Vaaler }\end{array}$ & June 2003 \\
\hline $\begin{array}{l}\text { No. 574: Reintroducing Intergenerational Equilibrium: Key Concepts } \\
\text { Behind the New Polish Pension System }\end{array}$ & Marek Góra & June 2003 \\
\hline $\begin{array}{l}\text { No. 573: Why Does FDI Go Where It Goes? New Evidence From the } \\
\text { Transition Economies }\end{array}$ & $\begin{array}{l}\text { Yuko Kinoshita and Nauro F. } \\
\text { Campos }\end{array}$ & June 2003 \\
\hline $\begin{array}{l}\text { No. 572: Private Savings in Transition Economies: Are There Terms of } \\
\text { Trade Shocks? }\end{array}$ & Abdur R. Chowdhury & May 2003 \\
\hline $\begin{array}{l}\text { No. 571: On the long-run determinants of real exchange rates for } \\
\text { developing countries: Evidence from Africa, Latin America and Asia }\end{array}$ & Imed Drine and Christophe Rault & May 2003 \\
\hline $\begin{array}{l}\text { No. 570: A re-examination of the Purchasing Power Parity using non- } \\
\text { stationary dynamic panel methods: a comparative approach for } \\
\text { developing and developed countries }\end{array}$ & Imed Drine and Christophe Rault & May 2003 \\
\hline $\begin{array}{l}\text { No. 569: How Important is Ownership in a Market with Level Playing } \\
\text { Field? The Indian Banking Sector Revisited }\end{array}$ & $\begin{array}{l}\text { Sumon Kumar Bhaumik and } \\
\text { Ralitza Dimova }\end{array}$ & May 2003 \\
\hline $\begin{array}{l}\text { No. 568: On Types of Trade, Adjustment of Labor and Welfare Gains } \\
\text { During Asymmetric Liberalizations }\end{array}$ & Yener Kandogan & May 2003 \\
\hline $\begin{array}{l}\text { No. 567: Technological Progress Through Trade Liberalization in } \\
\text { Transition Countries }\end{array}$ & Yener Kandogan & May 2003 \\
\hline $\begin{array}{l}\text { No. 566: Intra-industry Trade of Transition Countries: Trends and } \\
\text { Determinants }\end{array}$ & Yener Kandogan & May 2003 \\
\hline $\begin{array}{l}\text { No. 565: Local Protectionism and Regional Specialization: Evidence } \\
\text { from China's Industries }\end{array}$ & $\begin{array}{l}\text { Chong-En Bai, Yingjuan Du, } \\
\text { Zhigang Tao, Sarah Y. Tong }\end{array}$ & May 2003 \\
\hline No. 564: Corporate Governance and Market Valuation in China & $\begin{array}{l}\text { Chong-En Bai, Qiao Liu, Joe Lu, } \\
\text { Frank M. Song, and Junxi Zhang }\end{array}$ & May 2003 \\
\hline $\begin{array}{l}\text { No. 563: Revenue Sharing and Control Rights in Team Production: } \\
\text { Theories and Evidence From Joint Ventures }\end{array}$ & $\begin{array}{l}\text { Chong-En Bai, Zhigang Tao, and } \\
\text { Changqi Wu }\end{array}$ & May 2003 \\
\hline $\begin{array}{l}\text { No. 562: Financial Dependence, Stock Market Liberalizations and } \\
\text { Growth }\end{array}$ & Nandini Gupta and Kathy Yuan & May 2003 \\
\hline $\begin{array}{l}\text { No. 561: Growth and Regional Inequality in China During the Reform } \\
\text { Era }\end{array}$ & Derek Jones, Cheng Li and Owen & May 2003 \\
\hline $\begin{array}{l}\text { No. 560: Choice of Ownership Structure and Firm Performance: } \\
\text { Evidence from Estonia }\end{array}$ & $\begin{array}{l}\text { Derek Jones, Panu Kalmi, Niels } \\
\text { Mygind }\end{array}$ & May 2003 \\
\hline No. 559: Explaining Postcommunist Economic Performance & Lawrence P. King & May 2003 \\
\hline $\begin{array}{l}\text { No. 558: Tax Structure and the FDI: The Deterrent Effects of } \\
\text { Complexity and Uncertainty }\end{array}$ & $\begin{array}{l}\text { Kelly Edmiston, Shannon Mudd } \\
\text { and Neven Valev }\end{array}$ & Apr. 2003 \\
\hline No. 557: Provincial Protectionism & Konstantin Sonin & Apr. 2003 \\
\hline
\end{tabular}

